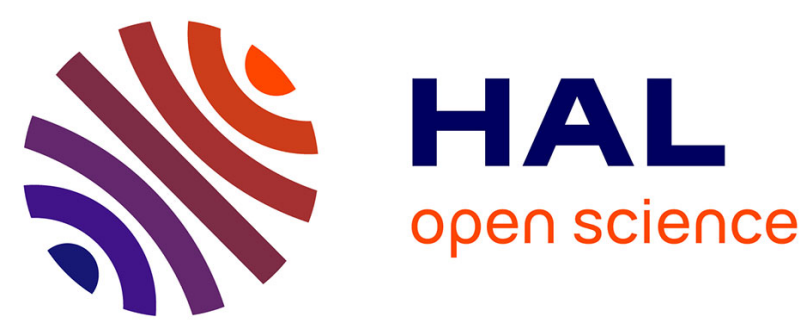

\title{
Sensitivity of tropical stratospheric ozone to rotational UV variations estimated from UARS and Aura MLS observations during the declining phases of solar cycles 22 and 23
}

Sébastien Bossay, Slimane Bekki, Marion Marchand, Virginie Poulain, Ralf

Toumi

\section{To cite this version:}

Sébastien Bossay, Slimane Bekki, Marion Marchand, Virginie Poulain, Ralf Toumi. Sensitivity of tropical stratospheric ozone to rotational UV variations estimated from UARS and Aura MLS observations during the declining phases of solar cycles 22 and 23. Journal of Atmospheric and Solar-Terrestrial Physics, 2015, 130-131, pp.96-111. 10.1016/j.jastp.2015.05.014 . insu-01158296

\section{HAL Id: insu-01158296 https://hal-insu.archives-ouvertes.fr/insu-01158296}

Submitted on 23 Jun 2015

HAL is a multi-disciplinary open access archive for the deposit and dissemination of scientific research documents, whether they are published or not. The documents may come from teaching and research institutions in France or abroad, or from public or private research centers.
L'archive ouverte pluridisciplinaire HAL, est destinée au dépôt et à la diffusion de documents scientifiques de niveau recherche, publiés ou non, émanant des établissements d'enseignement et de recherche français ou étrangers, des laboratoires publics ou privés. 
Sensitivity of tropical stratospheric ozone to rotational UV variations estimated from UARS and Aura MLS observations during the declining phases of solar cycles

\section{2 and 23}

Sébastien Bossay ${ }^{1}$, Slimane Bekki ${ }^{1}$, Marion Marchand ${ }^{1}$, Virginie Poulain ${ }^{2}$ and Ralf Toumi ${ }^{3}$

[1] \{Sorbonne Universités, UPMC Univ. Paris 06 ; Université Versailles St-Quentin ; CNRS/INSU, LATMOS-IPSL, France \}

[2] \{UPMC Univ. Paris 06 ; CNRS/INSU, LOCEAN-IPSL, France\}

[3] \{Imperial College, London, UK\}

Correspondance to : sebastien.bossay@latmos.ipsl.fr. Université Versailles Saint-Quentin (UVSQ) , LATMOS , Tour 45-46, 4e étage, Boîte 102, 4, Place Jussieu 75252 Paris Cedex 05, Phone : +33 (0)1 44274563

\section{Abstract}

The correlation between tropical stratospheric ozone and UV radiation on solar rotational time scales is investigated using daily satellite ozone observations and reconstructed solar spectra. We consider two 3-year periods falling within the descending phases of two 11-year solar cycles 22 (1991-1994) and 23 (2004-2007). The UV rotational cycle is highly irregular and even disappears for half a year during cycle 23. For the 1991-1994 period, ozone and $205 \mathrm{~nm}$ UV flux are found to be correlated between about 10 and $1 \mathrm{hPa}$ with a maximum of 0.29 at $~ 5$ 


\section{ACCEPTED MANUSCRIPT}

$\mathrm{hPa}$; ozone sensitivity (percentage change in ozone for 1 percent change in UV) peaks at $\sim 0.4$.

Correlation during cycle 23 is weaker with a peak ozone sensitivity of 0.2 . The correlation is found to vary widely, not only with altitude, but also from one year to the next with a rotational signal in ozone appearing almost intermittent. Unexpectedly, the correlation is not found to bear any relation with the solar rotational forcing. For instance, solar rotational fluctuations are by far the strongest during 1991-1992 whereas the correlation peaks at the end of 1993, a rotationally quiescent period. When calculated over sliding intervals of 1-year, the sensitivity is found to vary very strongly within both 3 -year periods; it is almost negligible

over the entire vertical profile during some 1-year intervals or reaches close to 1 around 2-5 $\mathrm{mb}$ for other intervals. Other sources of variability, presumably of dynamical origin, operate on the rotational spectral range and determine to a large extent the estimated solar rotational signal. Even considering 3 years of observations (corresponding to about 40 solar cycles), the extraction of the rotational solar signal does not appear to be robust during declining phases of 11-year solar cycles. As observational studies cover at best three 11-year solar cycles, it must be challenging to produce a reliable estimation of the 11-year solar cycle signal in stratospheric ozone, especially in the presence of decadal climate variability.

Ozone - stratosphere - solar variability - 27-days - photochemistry

\section{Introduction}

Solar radiation is the main source of input energy to the terrestrial atmosphere and, as such, it partly determines the Earth's radiative balance and climate. The total input energy is quantified with the Total Solar Irradiance (TSI). TSI varies on different time scales; the two most important cycles are the 11-year solar magnetic activity cycle (also called the Schwabe cycle) and the 27-day cycle (also called the Carrington solar rotational cycle). Changes in TSI 


\section{ACCEPTED MANUSCRIPT}

over an 11-year solar cycle are typically $0.1 \%$ only (about $0.24 \mathrm{~W} / \mathrm{m}^{2}$ ) at the top of Earth's atmosphere which is expected to have a relatively limited influence on climate. However, irradiance changes strongly depend on the considered wavelength region. The amplitude of irradiance changes during an 11-year solar cycle is greater at shorter wavelengths, with variations of $6-8 \%$ around $200-205 \mathrm{~nm}$ over a solar cycle, and even much greater near the Extreme UV (EUV) domain and Lyman alpha line $(121.57 \mathrm{~nm})$. The magnitude of variations in UV during the 27-day cycle is similar to that during the 11-year cycle. The 11-year solar cycle is caused by the variability of solar magnetic activity whereas the rotational cycle is caused by the longitudinally inhomogeneous distribution of magnetic field features (sunspots and faculae) at the surface of the rotating Sun.

Several datasets for the past Spectral Solar Irradiance (SSI, spectrally resolved solar irradiance) and Total Solar Irradiance (TSI) have been produced using different proxy-based reconstruction approaches (e.g. Lean et al. 2005; Krivova et al. 2009) and satellite measurements period. There is a consensus on an average TSI value of $1361 \pm 0.5 \mathrm{~W} \cdot \mathrm{m}^{-2}$ (Kopp and Lean, 2011; Ermolli et al., 2013). However, there are still very substantial disagreements on the variability and trend in TSI and SSI. For instance, the TSI during the Maunder minimum was estimated to be about 3-4 W/m $\mathrm{m}^{2}$ lower than the present TSI (Lean et al. 1995) whereas more recent reconstructions (Steinhilber et al., 2009; Fröhlich, 2009) derived a TSI change a factor 3 to 4 times smaller.

Regarding SSI, the situation appears to be more confused, notably for solar cycle 23. SSI measurements on the SORCE (Solar Radiation and Climate Experiment) satellite during the declining phase of solar cycle 23 (i.e. 2004 to 2008) show an unexpected behavior with a trend in UV (Harder et al., 2009) being found to be several times higher than all recent estimates for the 11-year cycles (e.g., Lean et al., 2005). More surprisingly, the trends in UV 


\section{ACCEPTED MANUSCRIPT}

radiation and TSI were found to be opposite to the trend in visible radiation (Harder et al., 2009), which is not at all consistent with proxy-based linear extrapolations used in reconstructing past irradiances (Pagaran et al., 2011). The substantial differences between the SSI datasets available for the declining phase of solar cycle 23 lead to different atmospheric and climate responses when they are used to force climate models (Shapiro et al. 2011). If SORCE SSI measurements are to be confirmed (Garcia, 2010), it will dramatically affect our understanding of the ozone and climate sensitivity to solar variations (Merkel et al. 2011; Haigh et al., 2010). It is worth pointing out that there is a strong possibility that the SORCE SIM instrument has suffered from degradation with time resulting in an overestimation of the UV decline during cycle 23 (Lean, and DeLand, 2012; DeLand and Cebula, 2012; Ermolli et al., 2013).

It is now acknowledged that the coupling between ozone and UV radiation, and the subsequent propagation of middle atmospheric solar-driven perturbations toward the lower atmosphere may play a very significant role in the overall atmospheric and climate responses to solar variability (Haigh, 2007; Haigh et al., 2010; Gray et al., 2010; Ermolli et al., 2013). Therefore, it is important to characterize the response of the stratosphere, notably ozone, to changes in solar spectral irradiance. Indeed, accurate observational characterizations are needed for evaluating chemistry-climate models that attempt to simulate the influence of solar variability on the middle atmosphere. Most observational and modeling studies have focused on the impact of solar ultraviolet irradiance on the tropical middle atmosphere, more particularly on ozone and temperature (Hood, 2004; Fioletov, 2009; Remsberg, 2008; Randel and Wu, 2007; Soukharev and Hood, 2006; Austin et al., 2007; Hood and Soukharev, 2012). These studies found a change in the range of 2 to $4 \%$ in ozone mixing ratio from solar maximum to solar minimum of an 11-year solar cycle with a maximum change occurring near $40 \mathrm{~km}$. 


\section{ACCEPTED MANUSCRIPT}

The purpose of the present study is to analyze the short-term (i.e. rotational timescales) solar forcing of tropical stratospheric ozone during the declining phases of different 11-year solar cycles. The sensitivity of stratospheric ozone to solar variability is a key constraint on models that attempt to simulate the response of the stratosphere to solar variations (Brasseur, 1993; Fleming et al., 1995; Chen et al., 1997). Studies of ozone variability on rotational timescales may not only improve our understanding of short-term solar-driven ozone variability but can also provide a valuable insight into the mechanisms driving the stratospheric response on longer solar time scales. The focus is on the rotational cycle because satellite time series cover many more rotational cycles than 11-year cycles. Solar UV irradiance and ozone have been monitored from satellite since 1978, which covers only about three 11-year solar cycles. During the last 3-4 decades, the solar signal was also certainly perturbed by other natural and anthropogenic influences (i.e. volcanic eruptions and increasing greenhouse gases concentrations) which could lead to substantial inaccuracy in the solar signal retrieved from observations and thus possible disagreements with model simulations that only account for solar perturbations. In addition, because of the natural variability of the Earth's atmosphere on inter-annual time scales, it is preferable to consider at least several 11-year cycles before one can safely extract a robust 11-year solar signal. Finally, the estimation of a solar signal in ozone variations on long timescales is more sensitive to long-term instrumental drifts than on shorter time scales. For these reasons, studies of the rotational cycle are expected to provide more statistically significant and robust results than studies of the 11-year solar cycle. Several studies have been carried out to determine the relationship between UV solar flux and stratospheric ozone on rotation timescales. Most analyzed satellite observations over selected parts of a single solar cycle: cycle 21 maximum for Hood (1986), cycle 22 descending phase for Zhou (1997) and Hood and Zhou (1998), and cycle 23 descending phase for Ruzmaikin (2007) and Dikty (2010). Others considered parts of two cycles: from cycle 21 maximum 


\section{ACCEPTED MANUSCRIPT}

phase to cycle 22 descending phase for Chandra et al. (1994), maxima and descending phases of cycles 21 and 22 for Zhou et al. (2000), and from cycle 21 maximum to cycle 23 descending phase for Fioletov (2009). Chemistry-climate models have also been used to determine the relationship between UV solar flux and tropical stratospheric ozone on solar rotation timescales (Brasseur, 1993; Williams et al., 2001; Rozanov et al., 2006; Austin et al., 2007; Gruzdev et al., 2009; Merkel et al., 2011). Comparing quantitative results from different studies can be challenging because data filtering, statistical methods, solar and ozone datasets and time periods can differ quite substantially. It is not possible to claim that they reflect real temporal changes in the ozone-UV relationship, possibly because of other timevarying sources of ozone variability, or to artifacts in the different methodologies in the solar signal estimation.

The present study is focused on the temporal evolution in the ozone-UV relationship. The objective is to explore possible inter-annual variations in the relationship on rotational timescales and assess to what extent it varies not only within the declining phase of 11-year cycle and also from one 11-year cycle to another. Indeed, the amplitude and coherence of short-term solar UV variations may vary between solar cycles. In addition, the ozone response to UV changes during the descending phase of two different solar cycles may not be identical because the average solar spectrum may have changed, thus preconditioning the atmosphere in different ways. Comparing two solar cycles is partly inspired by studies that analyzed how the response of stratospheric ozone to solar UV variations varied between two relatively similar cycles, cycles 21 and 22 (Chandra et al., 1994; Hood and Zhou, 1998). Fioletov (2009) analyzed the rotational solar signal in cycles 22 and 23 . None of these studies have investigated the year-to-year variability in the estimated ozone response. We consider ozone datasets obtained from different satellite plate-forms (UARS and AURA) but with a similar instrument (MLS, Microwave Limb Sounder). The MLS/UARS observations started on 19 


\section{ACCEPTED MANUSCRIPT}

September 1991 but their coverage became more intermittent in 1994 because the antenna scanning mechanism began to exhibit signs of wear and it was exacerbated by problems with the UARS power system. The MLS/AURA observations started on 13 august 2004. In order to consider the same solar cycle phase in the two MLS datasets, two 3-year periods are selected (from 10/1991 to 09/1994, and from 09/2004 to 08/2007). Both periods correspond to the descending phase of 11-year solar cycles, cycle 22 (1985-1996) and cycle 23 (1996-2009). There is a great deal of observational evidence that the solar cycle 23 was rather exceptional with respect to cycles 21 and 22. Cycle 23 decline in the peak and mean of the group sunspot number appears to be the largest since the onset of the Maunder Minimum (Lockwood et al., 2011) and thermospheric densities in 2007-2009 were also the lowest observed in a 43- year database with anomalies starting well before 2006 (Emmert et al., 2010), the primary cause being anomalously low levels of solar extreme ultraviolet irradiance (Solomon et al., 2010). Note that the current debate on the UV decline during the descending phase of cycle 23 (Ermolli et al., 2013) has no relevance here because there is a general agreement on the shortterm rotational variations between SORCE data, reconstructed data (Lean et al., 2005) and concurrent observations (DeLand and Cebula, 2012).

The solar rotational characteristics (major periodicities, correlation with short term solar variability,...) in the ozone time series are estimated from commonly used filtering and spectral techniques. All the datasets are processed and analyzed exactly with the same algorithms; that way, differences in solar rotational signals between the two cycles cannot be attributed to differences in statistical treatments. The solar variability is characterized with the $205 \mathrm{~nm}$ solar flux (Lean et al., 2005; Thuillier et al., 2012); this wavelength region is critical for stratospheric ozone photochemistry (Brasseur and Solomon, 2005). 


\section{ACCEPTED MANUSCRIPT}

The plan of the article is the following. Section 2 provides a brief description of data series and methods used in this study. Results are discussed in Section 3. A summary and conclusions can be found in Section 4.

\section{Data description}

\subsection{5nm solar flux}

As explained in the introduction, the solar input used in this study is the spectral irradiance at $205 \mathrm{~nm}$ (from both measurements and reconstructions). This wavelength is chosen because it is important for the ozone chemical budget throughout the stratosphere. It corresponds to a socalled window region that is positioned between two strong absorption bands: the SchumannRunge band of molecular oxygen and the Hartley band of ozone (Brasseur and Solomon, 2005). In this region, atmospheric absorption is very low and hence solar UV radiation penetrates deeply in the atmosphere, down to the lower stratosphere, where it photolyzes molecular oxygen $\left(\mathrm{O}_{2}\right)$ to produce $\mathrm{O}_{3}$. The $205 \mathrm{~nm}$ flux, called thereafter F205, has been commonly used in previous studies because it's a very good proxy for characterizing solar variability in the UV domain.

F205 is taken from semi-empirical reconstructions carried out with a well-established and widely used solar spectral irradiance model, the Naval Research Laboratory Solar Spectral Irradiance (NRL-SSI) reconstruction model. Below $400 \mathrm{~nm}$, spectral irradiances are derived from a multiple linear regression analysis of UARS/SOLSTICE (SOLar Stellar Irradiance Comparison Experiment on board Upper Atmospheric Research Satellite (Rottman et al., 1993)) observations (for more information, see Lean et al. (1997) and Lean (2000)). We use the NRL-SSI model to generate the time series of daily F205. 


\section{ACCEPTED MANUSCRIPT}

\subsection{Tropical stratospheric ozone}

The interest of this study is based on the use of two data sets of ozone over two different solar cycles which are measured by instruments using the same technique: the MLS instrument for both data series (MLS /Aura and MLS /UARS ozone data sets). The focus is on the tropics because the ozone response to solar variability is mostly driven by photochemistry in this region and thus easier to be interpreted. Time series of daily tropical ozone mixing ratios on UARS pressure levels are generated by averaging zonally all the MLS ozone profiles between $20^{\circ} \mathrm{N}$ and $20^{\circ} \mathrm{S}$ for a given day $(24 \mathrm{hr})$.

\subsubsection{MLS/UARS data (solar cycle 22)}

The Microwave Limb Sounder (MLS) is one of the ten UARS instruments. The UARS satellite was launched on 12 September 1991, into a $57^{\circ}$ inclination and a $585 \mathrm{~km}$ altitude orbit. Waters $(1989,1993)$ describe in detail the microwave limb-sounding technique. The ozone retrieval is based on $205 \mathrm{GHz}$ radiances. The typical 1- $\sigma$ precision for ozone mixing ratio measurements is $0.5 \mathrm{ppmv}$ (about $20 \%$ ) at $0.46 \mathrm{hPa}, 0.3 \mathrm{ppmv}$ (between 2 and 10\%) at 1 4.6 $\mathrm{hPa}$ and $0.2 \mathrm{ppmv}($ about 2-3\%) at 10-46 hPa. As shown in Hood and Zhou (1998), an artificial 36-day periodicity, caused by the UARS yaw maneuver cycle (Froidevaux, 1994), is present in zonally averaged MLS data. This periodicity is present at all latitudes and increases with increasing altitude. Hood and Zhou (1998) suggested to remove this artificial periodicity by considering only daytime measurement near a local time for zonal mean calculations. However, the fraction of daytime measurements over a small range of local time is so low that this approach leads to much larger sampling errors and time gaps in the zonal averages. That is why Hood and Zhou (1998) used both night and day measurements, as in this study. It has to be mentioned that ozone diurnal variations do not generally exceed $5 \%$, excepted at high latitudes (Sakazaki et al., 2013; Schanz et al., 2014). However, above $2 \mathrm{hPa}$, they become 


\section{ACCEPTED MANUSCRIPT}

very substantial (Parrish et al., 2014), increasing with altitude. Solar signals estimated from regression on ozone measurements at fixed local times (e.g. solar occultation measurements) are not affected by diurnal variations. However, in the case of measurements taken at local times varying from day to day (e.g. MLS), the diurnal cycle can introduce spurious variations in the temporal evolution of the daily zonal mean, increasing the solar signal-to-noise ratio and thus making much less accurate the estimation of the solar signal. This effect depends on the relative amplitudes of the ozone diurnal and solar variations and on the spatio-temporal sampling of the measurements.

\subsubsection{MLS/Aura data (solar cycle 23)}

The Microwave Limb Sounder (MLS) is one of the four instruments on board the Aura satellite, which was launched on 15 July 2004 into a sun-synchronous near-polar orbit around $705 \mathrm{~km}$ in order to study atmospheric chemistry and dynamics. Aura MLS is an advanced successor to the MLS instrument on UARS. Detailed information on the microwave technique in general and the Aura MLS instrument in particular is given in Waters (1993) and Waters et al. (2006). MLS observes a large suite of atmospheric parameters by measuring millimeterand submillimeter-wavelength thermal emission from Earth's limb with seven radiometers covering five broad spectral regions $(118,190,240,640 \mathrm{GHz}$ and $2.5 \mathrm{THz})$. The "standard product" of ozone is retrieved from radiance measurement near the $240 \mathrm{GHz}$. The version 2.2 of the MLS ozone product is used in this study. The Aura MLS fields of view point forward in the direction of orbital motion and vertically scan the limb in the orbit plane. That is leading to data coverage from $82^{\circ} \mathrm{N}$ to $82^{\circ} \mathrm{S}$ latitude on every orbit. Thus Aura MLS provides continuous daily sampling of both polar regions, with none of the temporal gaps from yaw maneuvers that occurred with UARS MLS. The MLS limb scans are synchronized to the Aura 


\section{ACCEPTED MANUSCRIPT}

orbit, with 240 scans per orbit at essentially fixed latitudes. This results in about 3500 scans per day, with an along-track separation between adjacent retrieved profiles of $1.5^{\circ}$ great circle angle. The longitudinal separation of MLS measurements set by Aura orbit, $10-20^{\circ}$ over low and middle latitudes, with much finer sampling in the polar regions. The vertical resolution is about $3 \mathrm{~km}$ in upper troposphere and stratosphere and about 4-6 km in mesosphere. The 1- $\sigma$ precision for ozone mixing ratio measurements is about 0.1 to 0.3 (corresponding to 2 to 15 $\%$ ) from $46 \mathrm{hPa}$ to $0.5 \mathrm{hPa}$.

\section{Results and discussion}

\subsection{Analysis of raw data}

Figure 1 shows the temporal evolution of the daily F205 from the NRL-SSI model (Lean et al., 2005) over the two last full 11-year solar cycles (cycles 22 and 23). The two 3-year periods considered in this study (from $10 / 1991$ to $09 / 1994$ and from $09 / 2004$ to $08 / 2007$ ) are highlighted in red in the figure; they both fall within a descending phase of an 11-year solar cycle.

The high-frequency variability in the F205 time series largely originates from the solar rotational cycle. For the sake of simplicity, the 3-year periods of cycles 22 and 23 will be referred thereafter as the 1991-94 period and the 2004-07 period respectively and the socalled 27-day solar cycle as the rotational cycle. Figures 2.a and 2.b show the FFT (Fast Fourier Transform) power spectra of F205 time series for the 1991-94 period (i.e. from $10 / 1991$ to $09 / 1994$ ) and the $2004-07$ period (i.e. from 09/2004 to $08 / 2007$ ) respectively. In both power density spectra, there is a broad signal between 20 and 35 days with a maximum around 27 days (indicated by a vertical dotted line). The broadness of the peak indicates that 


\section{ACCEPTED MANUSCRIPT}

the solar rotational modulation varies in period and intensity. The solar rotational modulation is stronger during the 1991-94 than the 2004-07 period.

A secondary peak around 13.5 days is also visible for both periods; its power density is about an order of magnitude smaller than the 27-day peak. This periodicity is mostly caused by the presence on the Sun surface of two sunspots which rotate with the same period but are separated by about $180^{\circ}$ in longitude (e.g. Bai, 2003; Zhang et al., 2007). These findings are in agreement with previous results (Fioletov, 2009). Using a range of solar proxies (Mg II, F10.7 cm, Lyman- $\alpha$, F205), Fioletov (2009) found that the 27-day solar rotational modulation dominated the solar variability during the solar maxima and that it tended to be much stronger during the maxima of cycles 21 and 22 than during cycle 23.

To follow the temporal variations in the intensities of the spectral components, continuous wavelet transforms (CWT) are computed. The CWT is based on the Morlet wavelet (Torrence and Compo, 1998) that has the advantage of being reasonably localized in both time and frequency. Figures 2.c and 2.d show CWT time-resolved power spectral density (also called scalogram) of F205 for the 1991-94 and 2004-07 period respectively. The "cone-of-influence" is represented with the slightly vertical solid lines at the bottom corners (indicated by arrows) that delimit the boundary regions where edge effects become important. The $95 \%$ confidence level is denoted with solid contour lines. The black vertical dotted lines distinguish the three 1-year intervals that are studied in section 3.3 (relative to the inter-annual analysis). In agreement with the FFT results, the broad rotational component centered at 27 days always dominates the power spectral density for both periods. The solar rotational component is stronger during the first year of the 3-year periods than the second and third year, which is 


\section{ACCEPTED MANUSCRIPT}

consistent with the descending phase of an 11-year solar cycle. Out of the two 3-year periods, the solar rotational fluctuations are the largest and well-marked during the first year of the 1991-1994 period because it includes about half a year of cycle 22 maximum (se Figure 1). The solar rotational signal varies quite strongly in time within the 3-year periods. The solar rotational periodicities disappear for several months at the end of 1993 during cycle 22 . The gaps are even more pronounced during cycle 23 with rotational periodicities disappearing completely at the beginning of 2006 and during half a year in 2007. This is expected because the existence of a clean and constant harmonic oscillation requires the presence on the Sun of long-lived and intense active regions, which was not always the case during cycle 23 , especially during periods of low activity. In agreement with our FFT analysis and Fioletov results (2009), there is a strong signal centered around 27 days in the F205 CWTs for both periods and again the signal is found to be stronger during the 1991-94 period than the 200407 period.

Let us now analyze the spectral components of the ozone time series and search for the presence of a solar rotational signal. A spectral analysis is carried out on the daily stratospheric ozone data averaged over the tropical band $\left[20^{\circ} \mathrm{S}-20^{\circ} \mathrm{N}\right]$. However, there are gaps in the MLS/UARS data, notably towards the end of the period. As a result, a Fourier transform analysis would require prior linear temporal interpolation of the data which could be problematic when the data gaps are too large. The method of normalized Lomb-Scargle periodogram (Lomb, 1976; Scargle, 1982) is better suited to the case of unequally sampled time series with gaps and provides the same spectral information as a Fourier transform. This normalized periodogram is based on fitting the data with harmonics series using least squares method. Figure 3 shows the Lomb-Scargle periodograms of MLS/UARS (1991-94 period) and MLS/Aura (2004-07 period) tropical ozone data at four different pressure levels (4.6 hPa, 


\section{ACCEPTED MANUSCRIPT}

$3.2 \mathrm{hPa}, 2.1 \mathrm{hPa}$ and $1.5 \mathrm{hPa}$ ) in the upper stratosphere. Note that the raw ozone time series contained very few spurious values that have been filtered out by removing measurements that are outside the 2- $\sigma$ range of the zonal average at each pressure level. The 4 left hand-side panels corresponding to the 1991-94 period indicate a prominent peak at about 35 days that is induced by the yaw-maneuver period of the MLS/UARS instrument as described previously (Froidevaux, 1994; Hood and Zhou, 1998). There are small peaks in the 20-30 days range that correspond to the frequency domain of the solar rotational cycle. The solar rotational cycle is irregular; it peaks around 27 days but can cover a rather wide period range, typically between

20 and 35 days. The four right hand-side panels corresponding to the 2004-07 period also show small peaks between 20 and 35 days but they are much weaker than for the 1991-94 period. There is a broad peak centered around 41 days which is certainly not due to the solar rotation. It has to be pointed out that none of the peaks within the 20-35 days range (Figure 3) are statistically significant at the $95 \%$ confidence level (not shown).

\section{Figure 3}

The analysis of ozone Lomb-Scargle periodograms is inadequate to retrieve significant solar rotational signatures in ozone time series. The same results (not shown) are also observed in FFT power spectra (after filling gaps using temporal interpolation) with again a broad peak around 35 days and 40 days for the 1991-94 and 2004-07 period respectively and small peaks in the 20-30 days range. The lack of significant peaks at solar rotational periodicities in the ozone power spectra indicates there are other stronger sources of high-frequency variability in stratospheric ozone, possibly of dynamical origin. It is likely that there are time intervals during the 3-year periods when the solar rotational periodicities are stronger or that the other 


\section{ACCEPTED MANUSCRIPT}

sources of variability are weaker. For this reason, it might be interesting to have a look at time-resolved power spectra.

Figure 4 presents CWTs results for MLS/UARS (left panels) and MLS/Aura (right panels) ozone time series on the same pressure levels $(4.6 \mathrm{hPa}, 3.2 \mathrm{hPa}, 2.1 \mathrm{hPa}$ and $1.5 \mathrm{hPa})$ as in Figure 3. For MLS/UARS (1991-94 period), there is no very noticeable signal apart from a patchy and broad signal covering a wide period domain, from 20 to almost 40 days, period during the second-half of 1992. In agreement with Lomb-Scargle periodograms (see Figure 3), the signal appears to peak at about 35 days and is present at all the pressure levels. For MLS/Aura (2004-07 period ), there is a strong and broad signal centered around 40-45 days periods, already seen in the Lomb-Scargle periodograms, present at all pressure levels at the beginning of 2007. There is also a weaker signal at similar periodicities at the $3.2 \mathrm{hPa}$ pressure level during the second half of 2005 . For both ozone time series, the strongest signals are found at $3.2 \mathrm{hPa}$ and $2.1 \mathrm{hPa}$. In summary, in contrast to F205, ozone CWTs, like LombScargle periodograms, do not show a prominent rotational signal in the raw ozone time series, especially during the 2004-07 period.

We then calculate the mean squared coherence between F205 (from NRL-SSI) and stratospheric ozone in order to identify the frequency domains over which solar irradiance and ozone are most correlated. Coherence represents the degree of correlation between two time series as a function of frequency or period. Figure 5 shows the mean squared coherence (defined as the ratio between the magnitude-squared cross-spectral density between solar and ozone time series over the autospectral densities of solar and ozone time series) between F205 and ozone from MLS/UARS (left hand-side panel) and from MLS/Aura (right-hand side panel) as a function of the period, between the 10 and 40 days, and pressure, between 46 and $0.1 \mathrm{hPa}$. Solid contour lines denote the $90 \%$ confidence level and vertical dotted lines indicate 


\section{ACCEPTED MANUSCRIPT}

the 27-day period. For MLS/UARS (1991-94 period), the coherence is strong and significant only between the periods of 20 and 28 days and between about 10 and $1 \mathrm{hPa}$ with a local maximum of about 0.7 at the 22-day period around $6 \mathrm{hPa}$. For MLS/Aura (2004-07 period), the coherence is much weaker and barely significant at the $90 \%$ confidence level. These differences between the two periods are consistent with results from Fioletov (2009) who found a weaker (not statistically significant) coherence during the solar maximum of cycle 23 than during the maxima of cycles 21 and 22.

As the periodicities in F205 and ozone series strongly vary with time (see Figures 2 and 4), we use the wavelet transform coherence (WTC) to follow the temporal evolution of the coherence. WTC is a method to estimate the mean squared coherence and phase lag between the time series as a function of both time and period/frequency. WTC is computed with the Matlab toolbox provided by Grinsted et al. (2004). Figure 6 shows the WTCs results between F205 and ozone at two pressure levels (4.6 and $3.2 \mathrm{hPa}$ ) for MLS/UARS ozone data (left panels) and MLS/Aura ozone data (right panels). The phase is shown as arrows with in-phase pointing right, anti-phase pointing left, and the solar leading ozone by $90^{\circ}$ pointing straight down.

Coherence fields look very patchy. It is not entirely unexpected. A spectral analysis over very small temporal intervals (corresponding to the temporal resolution of the WTC) is subject to large uncertainties because of the very small data samples. For MLS/UARS (1991-94 period), the most outstanding feature is an area of strong in-phase coherence, between the periods of about 16 and 35 days, lasting about 7-8 months (from the middle of 1993 to the beginning of 1994); it is present at the four pressure levels but it peaks at the $4.6 \mathrm{hPa}$ level. There is a secondary coherence maximum in the middle of 1993 at similar periodicities at $3.2 \mathrm{hPa}$ with phase arrows pointing unexpectedly straight up (i.e. a phase lag of about three quarter of a cycle). It is much more localized (lasting only a couple of months) and is possibly just caused 


\section{ACCEPTED MANUSCRIPT}

by some random correlation over a couple of months. For MLS/Aura (2004-07 period), a patchy area of strong and significant in-phase coherence is found at the relevant period range (16-35 days) at the $4.6 \mathrm{hPa}$ pressure level, it last about 6 months in 2005. Another small area of strong coherence is found at the beginning of 2006 but it only last a couple of months and is present at all pressure levels. On both WTC panels, small areas of strong coherence can be found outside the 16-35 days period range, especially at shorter periods. Some is certainly related to the sub-harmonic period (about 13.5 days) of the main solar rotational periodicity. However, they typically do not last more than a couple of months and hence could partly originate from random fluctuations. Coherence appears to be much weaker during the 200407 period. The most surprising is that the coherence waxes and wanes, without coinciding with time intervals during which the solar rotational forcing itself is strong. For instance, the F205 rotational periodicities are the most intense during 1992 (see Figure 2.c) whereas the coherence appears to peak around these periodicities but at the end of 1993.

\subsection{Analysis of filtered data}

In order to focus on the spectral domain where the correlation between solar activity and ozone (centered around 27 days) is the highest, most previous studies considered data filtered in the frequency domain. Therefore, we apply a digital filter previously used (Hood, 1986; Chandra, 1986; Keating et al., 1987; Hood and Zhou, 1998; Zhou et al., 2000). The filtering procedure consists of smoothing data with a 7-day running mean which removes short-term fluctuations. Linear trend and mean value are also removed from these smoothed time series. Finally, a 35-day running mean is subtracted from the data, removing long-term fluctuations 


\section{ACCEPTED MANUSCRIPT}

(e.g. seasonal, semi-annual, annual and QBO variations). The overall procedure is equivalent to a band-pass filter in the frequency domain. Others band-pass filters (Butterworth or Bessel) could have been used but, in order to make our results as comparable as possible, we use the same digital filter as in previous studies.

Tables 1 and 2 show the linear (Pearson) correlation coefficient between filtered solar and ozone time series for the two periods at 7 pressure levels, from 10 to $1.5 \mathrm{hPa}$. The mean of the standard errors, provided in the Tables, is about 0.1 .

As the previous results on raw data highlighted the large temporal variations in the periodicities of the time series and the almost intermittent nature of the coherence between F205 and ozone, correlation coefficients are also calculated for individual years to investigate inter-annual variability. The second column of the tables corresponds to the 3 -year intervals whereas the third, fourth and fifth columns correspond to individual years. 2- $\sigma$ errors on correlation coefficients are of the order of 0.1 . Correlation coefficients calculated over 3 years are positive at all the levels for the 1991-94 period (Table 1) with a maximum of 0.29 at 4.6 $\mathrm{hPa}$ whereas they are about two times smaller for the 2004-07 period and even negative at 1.5 $\mathrm{hPa}$. The correlation varies strongly, not only with altitude, but also from one year to another. When calculated over 1-year intervals, it is positive during the 3 years at only 2 pressure levels $(6.8$ and $4.6 \mathrm{hPa})$ for both periods and, even on these levels, inter-annual variations are quite substantial. For example, for the 1991-94 period, it varies from 0.3 (first year) to 0.16 (third year) at $6.8 \mathrm{hPa}$ and it varies from 0.21 (first year) to 0.42 (third year) at $4.6 \mathrm{hPa}$. On the other pressure levels (outside the 6.8-4.6 $\mathrm{hPa}$ range), there is at least a year out of three when the correlation is not statistically significant or even negative. 


\section{ACCEPTED MANUSCRIPT}

Additional tests are carried out in order to better estimate the errors in the correlation calculations and the possible effect of random fluctuations and the time interval on correlation results. We create two random synthetic time series with the same length and resolution (daily) as the solar and ozone time series. These random time series are filtered exactly in the same way (digital filter) as the real time series. Then, correlation coefficients between these two random time series are computed for different window sizes (i.e. time intervals) according to the following procedure. The total length of the time series is 1095 days (3 years); correlation coefficients are calculated over small windows covering the length of the time series. Successive windows overlap because each window is shifted by half of the window size. For instance, the first window size considered here (10 days) gives about 219 windows and the last considered window size (600 days) gives 2 windows.

For a given window size, correlation coefficients are calculated over all the windows and then mean and quantiles are calculated from all the correlation coefficients. This procedure of correlation calculations is applied to the random and real time series and results are compared in order to test if the correlation between solar and ozone is statistically significant whatever the window size. Figures 7.a shows the mean linear correlation coefficient (solid line) between the two random time series as well as the 0.75 (in blue) and 0.25 (in red) quantiles as a function of the window size (in days). Figures 7.b and 7.c present results for the solar and ozone time series for both periods at the pressure level of $4.6 \mathrm{hPa}$. The absolute value of the mean correlation stays below 0.1 for the random time series whatever the window size (see Figure 7.a). As expected, the dispersion, represented by the 0.25 and 0.75 quantiles, decreases with increasing window size for random and real time series. In the case of the largest window size (600 days, hence 2 windows), differences between the mean and quantiles do not exceed 0.1 . This is of the order of the mean $2-\sigma$ error calculated previously from the entire time series (i.e. equivalent to 1 window, see Tables 1 and 2). In contrast to the dispersion, the 


\section{ACCEPTED MANUSCRIPT}

mean value of the correlation coefficient varies little with the window size for random and real time series. This suggests that, whatever the window size (time interval) chosen to analyze the 3-year time series, the mean value of the correlation coefficient is robust. For the 1991-94 period (see Figure 7.b), the correlation coefficient remains close to +0.3 over the range of window size values (10 to 600 days). For the 2004-07 period (see Figure 7.c), it is about +0.2 , slightly decreasing from +0.25 to +0.17 with increasing window size, The mean correlation coefficient for the 2004-07 period is smaller than for the 1991-94 period but is still distinctively greater than 0.1 , the uncertainty estimated from the random time series.

As time lags in the ozone response to solar UV variability are not accounted for in the previous correlations calculations, we repeat them with time lags. The results are called crosscorrelations to differentiate them from the previous ones. Naturally, for a null time lag, the results are identical. Results are plotted in Figures 8.a and 8.b as a function of pressure and time lag for the 1991-94 and 2004-07 period respectively. The shaded areas indicate results statistically significant at confidence levels greater than 95\%. As expected, the maximum cross-correlation for the 1991-94 period is found on the $4.6 \mathrm{hPa}$ level with no significant time lag (see also Table 1); this maximum of 0.29 is close to the maximum of 0.35 found by Hood and Zhou (1998) on the same pressure level. The overall variation of the time lag with altitude shown in Figure 8.a is similar to that found in previous studies (Hood, 1986; Brasseur et al., 1987; Brasseur, 1993; Hood and Zhou, 1998) with a negative lag above 3-4 hPa (ozone leading the solar flux) and a positive lag below (ozone lagging the solar flux). Above $1.5 \mathrm{hPa}$ (upper stratosphere-lower mesosphere), the cross-correlation does not exceed 0.1 and is not statistically significant; this result is consistent with Hood and Zhou results (1998) also obtained with MLS ozone data. However, using SBUV ozone data, Hood (1986) found correlation coefficients exceeding 0.5 above $1.5 \mathrm{hPa}$. Hood and Zhou (1998) attributed these cross-correlations differences in the upper stratosphere-lower mesosphere to the strong 


\section{ACCEPTED MANUSCRIPT}

diurnal cycle of ozone there (Parrish et al., 2014). Indeed, regression results from ozone measurements at fixed or very slowly varying local times (e.g. SBUV data used by Hood (1986)) are not expected to be affected by diurnal variations. However, in the case of measurements taken over a wide range of local times that vary from one day to another (e.g. MLS nighttime and daytime measurements), the diurnal cycle introduce spurious fluctuations in daily zonal mean calculations, increasing the "noise" (non-solar variability) and thus making more difficult the estimation of a robust solar signal. It is therefore likely that MLS based analyses tend to underestimate the correlation between ozone and UV flux in the upper stratosphere and mesosphere. Ideally, only ozone measurements at the same local time should be considered in order to remove the diurnal variability in the time series. The crosscorrelation pattern for the 2004-07 period (Figure 8.b) is more distorted and noisy than for the 1991-94 period (Figure 8.a). The maximum cross-correlation (0.2) is smaller and is found at $10 \mathrm{hPa}$ with a time lag of +5 days (ozone lagging solar flux) instead of $6.8 \mathrm{hPa}$ for the correlation without time lag (Table 1) and instead of $4.6 \mathrm{hPa}$ for the 1991-94 period. Dikty et al. (2010) analyzed the correlation between SCIAMACHY (SCanning Imaging Absorption spectroMeter for Atmospheric CHartographY) ozone data and Mg II index during cycle 23 and found large variations in cross-correlation results depending on the considered phase; correlations were smaller during solar minimum conditions (2006-2007) than during solar maximum conditions (2003-2004). As expected, our cross-correlation results for the 2004-07 period are closer to Dikty et al. (2010) results for solar minimum conditions than maximum conditions.

Ozone response to solar irradiance changes has also been characterized in the literature in terms of sensitivity, which is defined as the percentage change in ozone for one percent change in solar UV. We derive the ozone sensitivity by linear regression of the filtered ozone time series on different pressure levels using only one independent variable (F205). Figures 


\section{ACCEPTED MANUSCRIPT}

8.c and 8.d show the sensitivity as a function of altitude for the 1991-94 period (MLS/UARS) and 2004-07 period (MLS/Aura), respectively. The dashed lines denote the $2 \sigma$ error. For the 1991-94 period, the sensitivity peaks at 0.4 (i.e. 0.4 percent change in ozone for one percent change in F205) around 4-5 hPa ( 35 km), in good agreement with Hood and Zhou (1998) results. For the 2004-07 period, the sensitivity profile is somewhat irregular and the sensitivity peaks at only 0.2 around $35 \mathrm{~km}$; it is consistent with a peak value of 0.15 found on the same level by Dikty et al. (2010) for the 2006-2007 period (that best overlaps the 3-year period considered here).

\subsection{Analysis of inter-annual variations}

Time-resolved power spectra (see Figure 6) and correlations coefficients calculated over 1year intervals (Tables 1 and 2) indicate that the link between solar UV irradiance and ozone appears to be very intermittent. To investigate further the inter-annual variations, we repeat the cross-correlation/sensitivity analyses on 1-year intervals after having divided each period into three 1-year intervals, as done in Tables 1 and 2 . In principle, a 1-year interval should correspond to an average of about a dozen solar rotational cycles. Though one has to keep in mind the non-solar ozone variability, one year of data may appear to be sufficiently long for the extraction of a robust solar rotational signal in ozone time series. For comparison, estimations of the 11-year solar cycle signal have been carried out with ozone time series covering at best 3 solar cycles. Figures 9 and 10 show the cross-correlation between filtered solar flux and tropical stratospheric ozone and ozone sensitivity for the three 1-year intervals of the 1991-94 and 2004-07 period. The results for the whole periods (3-year intervals) are shown in Figure 8.

For both periods, cross-correlation and sensitivity results vary substantially from one year to another. For the 1991-94 period, the correlation (at null time lags) and ozone sensitivity 


\section{ACCEPTED MANUSCRIPT}

remains positive during the 3 years between only about 8 and $2 \mathrm{hPa}$. Above and below this altitude range, cross-correlation results for the three 1-year intervals are very different with no clear pattern emerging. The correlation is stronger during the third year (from 10/1993 to 09/1994) than during the first and second 1-year interval. The cross-correlation peaks at 0.42 at $4.6 \mathrm{hPa}$ for the third year whereas it peaks 0.22 and 0.32 for the first and second year, respectively. In the same way, the sensitivity peaks at only 0.2 during the first year whereas it reaches about $0.5-0.6$ (\% change in ozone for $1 \%$ change in solar UV) at around 3-4 $\mathrm{hPa}$ during the second and third year. It is in contrast with the F205 rotational periodicities being much more intense during the first year than during the second and third year (see Figure 2.c). This finding is rather surprising because F205 rotational fluctuations and hence ozone forcing are by far the strongest during the first year (see Figure 2), being the closest to the maximum of cycle 22. As a result, correlation and ozone responses are expected to be the largest during the first year. This tendency has been confirmed by several observational studies. For example, Hood (1986) analyzed almost 2 years (November 78 to mi-October 80 ) of SBUV tropical ozone data during cycle 21 and found that correlation with solar UV variations tended to be larger during time periods of relatively strong 27-day solar UV modulations. In the same way, Zhou et al. (2000) examined four different of about 3 years corresponding to solar maximum and declining phases in solar cycles 21 and 22 and found the largest rotational solar signal in SBUV ozone time series during solar maximum periods. The solar signal was difficult to detect in the declining phases. Fioletov (2009) considered of two and half 11-year solar cycles (cycles 21 and 22, first half of cycle 23) and showed that a large fraction of the ozone variance could be attributed to solar rotational fluctuations during the periods of high solar activity whereas the solar rotational signal was barely significant during the periods of low solar activity (Fioletov, 2009). On the other hand, our results are consistent with Hood and Zhou (1998) who analyzed MLS/UARS ozone data for the 1991-1994 period and found a 


\section{ACCEPTED MANUSCRIPT}

correlation two times stronger during the last half of the period than during the first half. Hood and Zhou (1998) speculated that it was the result of an artifact of either instrumental or geometric (local time coverage) problems that may have affected the earliest part of the MLS/UARS ozone record more than the later part. However, there is no evidence for it in the dataset or, to our best knowledge; no such problems have been reported for MLS data in the literature. Therefore, it is more likely to reflect real ozone variability. The extraction of the solar signal in the ozone time series does not depend only on the intensity of the solar rotational forcing but also on non-solar, presumably dynamical, sources of ozone variance (operating on solar rotational periodicities) that can be viewed as noise in the solar signal estimation process. It is possible that non-solar fluctuations may have been much larger the first year than the second and third year of the 1991-94 period and would have degrading the signal-to-noise ratio, making the signal extraction more difficult, even if this solar rotational signal must have been greater the first year.

For the 2004-07 period, there are very large inter-annual variations in cross-correlation and sensitivity, notably in terms of amplitude, altitude of maximum and, more generally, overall shape, from one year to another (see Figure 10) throughout the stratosphere. It is not possible to highlight any common patterns among the different years. The results also differ strongly from the 1991-94 results, except for the sensitivity profile of the second year that somewhat resembles to the profiles for the second and third year of the 1991-94 period between about 3 and $8 \mathrm{hPa}$. Although the rotational solar forcing is the strongest during the first year of the 2004-07 period (see Figure 2.d), the sensitivity is the weakest throughout the vertical profile during that year. As for the 1991-94 period, the most likely explanation is that non-solar ozone fluctuations were much larger during the first year than the second and third year of the 2004-07 period, "masking” the solar rotational signal. 


\section{ACCEPTED MANUSCRIPT}

To explore further the inter-annual variability in ozone sensitivity, sensitivity profiles are calculated over 24 1-year intervals (per 3-year period) obtained by shifting a 1-year sliding window by a month. Figure 11 shows the mean of the 24 sensitivity profiles and 2-sigma deviations for the two 3-year periods. Though sensitivity values are slightly weaker, the profiles of mean sensitivity are reasonably similar to the profiles calculated over the 3-year periods (see Figure 8). As in Figure 8, the mean sensitivity peaks between about 1 and $10 \mathrm{mb}$ typically and are much smaller for the 2004-07 period than for 1991-94 period. The amplitude of the 2-sigma deviations shows that ozone sensitivities calculated over 1-year intervals can vary widely with very small sensitivities for some 1-year intervals and sensitivities even approaching 1 (between about 2 and $5 \mathrm{hPa}$ ) for other intervals.

\section{Summary and concluding remarks}

The purpose of the present observational study is to estimate the solar rotational signal in tropical stratospheric ozone and its inter-annual variability. Based on the availability of MLS stratospheric ozone data on-board the UARS satellite and AURA satellite, we consider two 3year periods falling within the descending phases of two successive 11-year solar cycles, from $10 / 1991$ to $09 / 1994$ for cycle 22 and from $09 / 2004$ to $08 / 2007$ for the rather exceptional cycle 23. We choose the solar irradiance at $205 \mathrm{~nm}$ (F205), a key quantity in ozone photochemistry, and the daily F205 time series is generated from a well-established and widely used solar reconstruction model (Lean et al., 2005). We have also tested other UV proxies, notably from satellite observations (UARS/SOLSTICE for cycle 22 and SORCE/SOLSTICE (SORCE/Solar Stellar Irradiance Comparison Experiment (Snow et al., 2005) during cycle 23). Results obtained with these observational UV time series are not presented here because they are very close to those obtained with the NRL-SSI F205 time series. 


\section{ACCEPTED MANUSCRIPT}

Power spectra of F205 indicate a broad peak centered around 27 days, which is stronger for 1991-94 period than 2004-07 period. Time-resolved spectral analyses show that rotational periodicities are highly variable in the 205-nm flux time series; they even disappear for half a year during the 2004-07 period. In contrast to the $205 \mathrm{~nm}$ flux, no prominent solar rotational signature is found in the raw stratospheric ozone time series for both periods.

The level of correlation between stratospheric ozone and F205 variations for the 1991-94 period is found to be strong and significant (at the $90 \%$ confidence level) over periods ranging from 20 to 28 days and between about 10 and $1 \mathrm{hPa}$ with a maximum coherence of 0.7 at the 22-day period around 6-7 $\mathrm{hPa}$. The coherence is weaker for the 2004-07 period. This is consistent with results from Fioletov (2009) who found a weaker (not statistically significant) coherence during the solar maximum of cycle 23 than during the maxima of cycles 21 and 22 . Time-resolved spectra (wavelet transform coherence, WTC) reveal that the coherence appears to be almost intermittent with very patchy WTC fields. The most significant feature is a strong coherence within the solar rotational periodicities lasting 7-8 months, from the middle of 1993 to the beginning of 1994 . Overall, coherence is much weaker during the 2004-07 period. The most unexpected feature is that the coherence waxes and wanes, without coinciding with time intervals during which the solar rotational forcing itself is strong. For instance, the solar $205 \mathrm{~nm}$ rotational periodicities are the most intense during 1992 (see Figure 2.c) whereas the coherence appears to peak within these periodicities but at the end of 1993.

We also carry out the analysis with times series filtered in the frequency domain. Correlation coefficients calculated over the 3 years of filtered data are found be positive over the 10 to 1.5 $\mathrm{hPa}$ pressure range for the 1991-94 period with a maximum of 0.29 at $4.6 \mathrm{hPa}$ whereas they are about two times smaller for the 2004-07 period and even negative at $1.5 \mathrm{hPa}$. Time lag tends to be negative above $3-4 \mathrm{hPa}$ and positive below. This overall pattern is similar to that found in previous studies (Hood, 1986; Brasseur et al., 1987; Brasseur, 1993; Hood and Zhou, 


\section{ACCEPTED MANUSCRIPT}

1998). The cross-correlation pattern for the 2004-07 period is much more distorted and noisy than for the 1991-94 period. Correlation has also been quantified in terms of ozone sensitivity (i.e. ozone percentage change per $1 \%$ change in the solar index, here $205 \mathrm{~nm}$ irradiance). For the 1991-94 period, the sensitivity peaks at 0.4 (i.e. 0.4 percent change in ozone for 1 percent change in $205 \mathrm{~nm}$ irradiance) around 4-5 $\mathrm{hPa}(\sim 35 \mathrm{~km})$, in good agreement with Hood and Zhou (1998) results. For the 2004-07 period, the sensitivity profile is somewhat irregular and sensitivity peaks at only 0.2, which is in agreement with Dikty et al. (2010) results.

In order to explore to what extent correlation and sensitivity vary, not only with altitude, but also from one year to another, we calculate the correlation coefficients over 1-year intervals. A 1-year interval should correspond to an average of about a dozen solar rotational cycles. For both periods, cross-correlation and sensitivity results vary very substantially from one year to another. For the 1991-94 period, correlation and ozone sensitivity remain positive during the 3 years between only about 8 and $2 \mathrm{hPa}$. Above and below this altitude range, cross-correlation results for the three 1-year intervals are very different with no clear pattern emerging. The correlation is stronger during the third year (from 10/1993 to 09/1994) than during the first and second 1-year interval. The sensitivity peaks at only 0.2 during the first year whereas it reaches about $0.5-0.6$ (\% change in ozone for $1 \%$ change in solar UV) at around 3-4 hPa during the second and third year. It is in contrast with the fact that F205 rotational periodicities are much more pronounced during the first year than during the second and third year. For the 2004-07 period, the inter-annual variations in cross-correlation and sensitivity are much larger, notably in terms of amplitude, altitude of maximum and, more generally, overall shape of the profiles. It is difficult to highlight any common features. An interesting similarity with the 1991-1994 period is that, although the rotational solar forcing is the strongest during the first year of the 2004-07 period, the ozone sensitivity is the weakest throughout the pressure range of interest (from about 10 to $1 \mathrm{mb}$ ). This finding, common to 


\section{ACCEPTED MANUSCRIPT}

both periods, is unexpected. When the solar rotational fluctuations are well marked with large amplitudes, notably around the maxima of 11-year cycles, ozone response and correlation are expected to be the largest. A part from a study by Hood and Zhou (1998) who analyzed MLS/UARS ozone data for the 1991-94 period, this tendency has been confirmed by several observational studies (Hood, 1986; Zhou et al., 2000; Fioletov, 2009). The same analysis was repeated for 24 1-year intervals (per 3-year period) obtained by shifting a 1-year sliding window by a month. Ozone sensitivity is found to be almost negligible for some 1-year intervals whereas it can even approach 1 between about 2 and $5 \mathrm{hPa}$ for other intervals. Obviously, the lack of correlation during some intervals should not be interpreted as an absence of influence of UV changes on ozone; it is more indicative of the presence of other sources of ozone variability that degrades the signal-to-noise ratio and hence the estimation of the solar rotational signal. It makes the correlation between ozone and solar UV radiation look somewhat intermittent. Our results suggest that one year of ozone data (covering on average 12 solar rotational cycles) is insufficient to extract a robust solar rotational signal because of other sources of ozone variability, even during periods of strong solar rotational activity (like during 1991). Even considering 3 years of observations (corresponding to about 40 solar cycles), we find the estimation of the rotational solar signal is not reliable during the declining phase of 11-year solar cycle. Finally, it is worth pointing out that observational studies estimating the 11-year solar cycle signal in stratospheric ozone time series have covered at best three 11-year solar cycles (Fioletov, 2009). As stratospheric ozone is also influenced by decadal climate variability (Toumi et al., 2001), it is not clear to what extent the estimation of the 11-year solar cycle signal is robust.

The relationship between ozone and the 27-day solar variability has also been studied with Chemistry Chemical Models (CCMs) (e.g. Williams et al., 2001; Rozanov et al., 2006; Austin et al., 2007; Gruzdev et al., 2009). We now examine the consistency of our observational 


\section{ACCEPTED MANUSCRIPT}

results with these model results. Even though all atmospheric processes and their couplings are not perfectly represented in models, CCMs can allow us to evaluate the expected ozone sensitivity to solar forcing and, thus, improve our comprehension of the processes linking stratospheric ozone and solar UV irradiance. As for observational results, model results can vary from one CCM study to another. Austin et al. (2007) calculated a peak tropical ozone sensitivity of $0.4 \%$ per $1 \%$ change in $205 \mathrm{~nm}$ solar flux which is in good agreement with our peak value for the 3 years of cycle 22 but not with cycle 23 results. In addition, their peak is located at about $2 \mathrm{hPa}$ instead of $4.6 \mathrm{hPa}$. Gruzdev et al. (2009) calculated the same maximum sensitivity of 0.4 but at $40 \mathrm{~km}$. Rozanov et al. (2006) found a similar result with sensitivity values scattered between 0.2 and 0.8 in the stratosphere. In all these model studies, there seems to be a strong inter-annual variability in the ozone sensitivity, though not fully quantified. The inter-annual variability in the sensitivity was attributed to nonlinearities in the chemistry (Austin et al., 2007) or to the dynamical state of the background atmosphere (Gruzdev et al., 2009). It is important to point out that the quantitative agreement between our study and some model results on the value of the peak ozone sensitivity might also be fortuitous. It only holds for cycle 22 and, even during this cycle, our observation-derived sensitivity varies widely from one year to another.

Finally, the differences between results from cycle 22 and cycle 23 could also be attributed to the fact that they do not cover exactly the same part of the descending phase of 11-year solar cycles (see Figure 1). The 3 years of cycle 22 considered here are closer to the 11-year solar maximum (including even about 6 months of cycle 22 solar maximum), than the 3 years of cycle 23. As studies with CCMs are not constrained by the availability of ozone observations, several 11-year cycles might be required in order to investigate how the solar-ozone relationship on rotational timescales varies over and within several entire 11-year cycle (ascending phase, maximum and minimum phases) The current 11-year cycle (cycle 24) is 


\section{ACCEPTED MANUSCRIPT}

intriguing. The amplitude of this cycle is even smaller than the previous three cycles, suggesting that it might even be more atypical than cycle 23 . It would be interesting to study it and investigate whether the ozone response to solar rotational variability is also different.

\section{Acknowledgments}

We thank Thierry Dudok de Wit for his very valuable and constructive comments and suggestions on the work and first version of the manuscript. The solar reconstructions can be obtained from the LASP Interactive Solar Irradiance Datacenter (LISIRD, http://lasp.colorado.edu/lisird). We thank the Ether CNES/CNRS-INSU thematic center for providing ozone data (http://www.pole-ether.fr). This work was supported by the grant SOLSPEC from the Centre d'Etude Spatiale (CNES).

\section{References}

Austin, J., Hood, L. L., Soukharev, B. E., 2007. Solar cycle variations of stratospheric ozone and temperature in simulations of a coupled chemistry-climate model, Atmos. Chem. Phys., 6 , $12,121-12,153$.

Bai, T., 2003. Hot spots for solar flares persisting for decades: Longitude distributions of lares of cycles 19-23, Astrophys. J., 585, 1114-1123, doi: 10.1086/346152.

Brasseur, G, Rudder, A. D., Keating, G. M., Pitts, M. C., 1987. Response of middle atmosphere to short-term solar ultraviolet variations: 2. Theory, J. Geophys. Res. 92(D1), 903-914.

Brasseur, G., 1993. The response of the middle atmosphere to long-term and short-term solar variability: A two-dimensional model, J. Geophys. Res., 98, 23,079-23,090, doi:10.1029/93JD02406. 


\section{ACCEPTED MANUSCRIPT}

Brasseur, G., Solomon, S., 2005. Aeronomy of the middle atmosphere: Chemistry and physics of the stratosphere and mesosphere, Third edition, Springer, Dordrecht, the Netherlands, 646 pp.

Chandra, S., 1986. The solar and dynamically induced oscillations in the stratosphere, $J$. Geophys. Res., 99, 20, 665-20, 671, doi:10.1029/JD091ID02P02719.

Chandra, S., McPeters, R. D., 1994. The solar cycle variation of ozone in the stratosphere inferred from Nimbus 7 and NOAA 11 satellites, J. Geophys. Res., 99, 20,665-20,671, doi:10.1029/94JD02010.

Chandra, S., Froidevaux, L., Waters, J. W., White, O. R., Rottman, G. J., Prinz, D. K., Brueckner, G. E., 1996. Ozone variability in the upper stratosphere during the declining phase of the solar cycle 22, J. Geophys. Lett., 23, 21, 2935-2938, doi:10.1029/96GL02760.

Chen, L., London, J., Brasseur, G., 1997. Middle atmospheric ozone and temperature responses to solar irradiance variations over 27-day periods, J. Geophys. Res., 102(D25), 29957-29979, doi:10.1029/97JD02467.

Compo, G., Whitaker, J., Sardeshmukh, P. et al., 2011. The Twentieth Century Reanalysis Project. Q. J. R. Meteorol. Soc. 137: 1-28, doi:10.1002/qj.776.

DeLand, M. T., Cebula, R. P., 2012. Solar UV variations during the decline of cycle 23, J. Atmospheric and Solar-Terrestrial Physics, v. 77, 225-234.

Dikty, S., Weber, M., von Savigny, C., Sonkaew, T., Rozanov, A., Burrows, J. P., 2010. Modulations of the 27 day solar rotation signal in stratospheric ozone from Scanning Imaging Absorption Spectrometer for Atmospheric Cartography (SCIAMACHY) (2003-2008), J. Geophys. Res., 115, D000I15, doi:10.1029/2009JD012379.

Emmert, J. T., Lean J., Picone, L., 2010. Record-low thermospheric density during the 2008 solar minimum, Geophys. Res. Lett., 37, L12102, doi: 10.1029/2010GL043671.

Ermolli, I., Matthes K., Dudok de Wit T., Krivova N. A., Tourpali K., Weber M., Unruh Y. C., Gray L., Langematz U., Pilewskie P., Rozanov E., Schmutz W., Shapiro A., Solanki S. K., and Woods T. N., 2013. Recent variability of the solar spectral irradiance and its impact on climate modelling, Atmospheric Chemistry and Physics, 13, pp. 3945-3977, doi: 10.5194/acp13-3945-2013.

Eyring, V., et al., 2013. Long-term ozone changes and associated climate impacts in CMIP5 simulations, J. Geophys. Res. Atmos., 118, 5029-5060, doi:10.1002/jgrd.50316.

Fioletov, V. E., 2009. Estimating the 27-day and 11-year solar cycle variations in tropical upper stratospheric ozone, J. Geophys. Res., 114, D02302, doi:10.1029/2008JD010499.

Fleming, E. L., Chandra, S., Jackman, C. H., Considine, D. B., Douglass, A. R., 1995. The middle atmospheric response to short and long term solar UV variations: Analysis of observations and 2D model results, J. Atmos. Terr. Phys., 57, 333-365. 


\section{ACCEPTED MANUSCRIPT}

Fröhlich, C., 2009. Evidence of a long-term trend in total solar irradiance, Astron. Astrophys., 501, L27-L30, doi:10.1051/00004-6361/200912318.

Froidevaux, L., Waters, J. W., Read, W. G., Elson, L. S., Flower, D. A., Jarnot, R. F., 1994. Global Ozone Observations from the UARS MLS: An Overview of Zonal-Mean Results. $J$. Atmos. Sci., 51, 2846-2866

Garcia R. R., 2010. Atmospheric Physics: Solar surprise?, Nature, 467, 7316, 668-669.

Gray, L. J., Beer, J., Geller, M., Haigh, J. D., Lockwood, M., Matthes, K., Cubasch, U., Fleitmann, D., Harrison, G., Hood, L. L., Luterbacher, J., Meehl, G. A., Shindell, D., van Geel, B., White, W. 2010. Solar influences on climate, Rev. Geophys., 48, RG4001, doi:10.1029/2009RG000282.

Grinsted, A., Moore, J. C., Jevrejeva, S., 2004. Application of the cross wavelet transform and wavelet coherence to geophysical time series, Nonlin. Processes Geophys., 11, 561-566, doi:10.5194/npg-11-561-2004.

Gruzdev, A. N., Schmidt, H., Brasseur, G. P., 2009. The effect of the solar rotational irradiance variation on the middle and upper atmosphere calculated by a three-dimensional chemistry climate model, Atmos. Chem. Phys., 8, 1113-1158.

Haigh, J. D., 2007. The Sun and the Earth's Climate, Living Reviews in Solar Physics 4.

Haigh, J. D., Winning, A. R., Toumi, R., Harder, J. W., 2010. An influence of solar spectral variations on radiative forcing of climate, Nature, 467, 696-699.

Harder, J. W., Fontenla, J. M., Pilewskie, P., Richard, E. C., Woods, T. N., 2009. Trends in solar spectral irradiance variability in the visible and infrared, Geophys. Res. Lett., 36, L07801, doi:10.1029/2008GL036797.

Hood, L. L., 1986. Coupled stratospheric ozone and temperature response to short-term changes in solar ultraviolet flux: An analysis of Nimbus 7 SBUV and SAMS data, $J$. Geophys. Res., 91(D4), 5264-5276, doi:10.1029/JD091ID04P05264.

Hood, L. L., Zhou, S., 1998. Stratospheric effects of 27-day solar ultraviolet variations: An analysis of UARS MLS ozone and temperature data, J. Geophys. Res., 103(D3), 3629-3638.

Hood, L. L., 2004. Effects of solar UV variability on the stratosphere, in Solar Variability and Its Effect on the Earth's Atmosphere and Climate System, Geophys. Monogr. Ser., vol. 14, edited by J. Pap et al., pp. 283-303, AGU, Washington, D. C.

Hood, L.L. and B. E. Soukharev, 2012. The Lower-Stratospheric Response to 11-Yr Solar Forcing: Coupling to the Troposphere-Ocean Response. J. Atmos. Sci., 69, 1841-1864. doi: http://dx.doi.org/10.1175/JAS-D-11-086.1

Kopp, G., Lean, J. L., 2011. A new, lower value of total solar irradiance: Evidence and climate significance, Geophys. Res. Lett., 38, L01706, doi:10.1029/2010GL045777. 


\section{ACCEPTED MANUSCRIPT}

Krivova, N. A., Solanski, S. K., Wenzler, T., Podlipnik, B., 2009. Reconstruction of solar UV irradiance since 1974, J. Geophys. Res., 114, D00I04, doi10.1029/2009JD012375.

Lean, J., Beer, J., Bradley, R. 1995. Reconstruction of solar irradiance since 1610: Implications for climate change, Geophys. Res. Lett., 22, 3195-3198, doi:10.1029/95GL03093.

Lean, J., 2000. Evolution of the Sun's spectral irradiance since the Maunder Minimum, Geophys. Res. Lett., 27, 2425-2428,doi:10.1029/2000GL000043.

Lean, J., Rottman, G., Harder, J., Kopp, G., 2005. SORCE contributions to new understanding of global change and solar variability, Sol. Phys., 230, 27.

Lean, J., DeLand, M. T., 2012. How does the Sun's spectrum vary? J. of Climate, v. 25, 25552560.

Lockwood, M., 2011. Was UV spectral solar irradiance lower during the recent low sunspot minimum? J. Geophys. Res., 116, D16103, doi:10.1029/2010JD014746.

Lomb, N. R., 1976. Least-Squares Frequency Analysis of Unevenly Spaced Data, Astrophysical and Space Science, 39, pp. 447-462.

Marchand, M., Keckhut, P., Lefebvre, S., Claud, C., Cugnet, D., Hauchecorne, A., Lefèvre, F., Lefebvre, M.P., Jumelet, J., Lott, F., Hourdin, F., Thuillier, G., Poulain, V., Bossay, S., Lemennais, P., David, C., Bekki, S., 2012. Dynamical amplification of the stratospheric solar response simulated with the Chemistry-Climate model LMDz-Reprobus, J. Atmos. Sol.-Terr. Phys., 75-76, 147-160, doi:10.1016/j.jastp.2011.11.008.

Merkel, A. W., Harder, J. W., Marsh, D. R., Smith, A. K., Fontenla, J. M., Woods, T. N., 2011. The impact of solar spectral irradiance variability on middle atmospheric ozone, Geophys. Res. Lett., 38, L13802, doi:10.1029/2011GL047561.

Pagaran J., Weber, M., DeLand, M. T., Floyd, L. E., Burrows, J. P., 2011. Solar spectral irradiance variations in 240-1600 nm during the recent solar cycles 21-23, Solar Physics, 272, 159-188, doi: 10.1007/s11207-011-9808-4

Parrish, A., Boyd, I. S., Nedoluha, G. E., Bhartia, P. K., Frith, S. M., Kramarova, N. A., Connor, B. J., Bodeker, G. E., Froidevaux, L., Shiotani, M., and Sakazaki, T., 2014. Diurnal variations of stratospheric ozone measured by ground-based microwave remote sensing at the Mauna Loa NDACC site: measurement validation and GEOSCCM model comparison, Atmos. Chem. Phys., 14, 7255-7272.

Randel, W. J., Wu, F., 2007. A stratospheric ozone profile data set for 1979-2005: Variability, trends, and comparisons with column ozone data, J. Geophys. Res., 112, D06313, doi:10.1029/2006JD007339. 


\section{ACCEPTED MANUSCRIPT}

Remsberg, E. E., et al., 2008. Assessment of the quality of the Version 1.07 temperatureversus-pressure profiles of the midlle atmosphere from TIMED/SABER, J. Geophys. Res., 113, D17101, doi:10.1029/2008JD010013.

Rozanov, E., Egorova, T., Schmutz, W., \& Peter, T., 2006. Simulation of the stratospheric ozone and temperature response to the solar irradiance variability during sun rotation cycle. Journal of Atmospheric and Solar-Terrestrial Physics, 68(18), 2203-2213.

Rottman, G. J., Woods, T. N., Sparn, T. P., 1993. 'Solar Stellar Irradiance Comparison Experiment 1: 1. instrument design and operation', J. Geophys. Res. 98, 10,667-10,678.

Ruzmaikin, A., Santee, M. L., Schwartz, M. J., Froidevaux, L., Pickett, H. M., 2007. The 27day variations in stratospheric ozone and temperature: New MLS data, Geophys. Res. Lett., 34, L02819, doi:10.1029/2006GL028419.

Sakazaki, T., Fujiwara, M., Mitsuda, C., Imai, K., Manago, N., Naito, Y., Nakamura, T., Akiyoshi, H., Kinnison, D., Sano, T., Suzuki, M., and Shiotani, M., 2013. Diurnal ozone variations in the stratosphere revealed in observations from the Superconduct-ing Submillimeter-Wave Limb-Emission Sounder (SMILES) on board the International Space Station (ISS), J. Geophys. Res. Atmos., 118, 2991-3006, doi:10.1002/jgrd.50220.

Scargle, J. D., 1982. Studies in Astronomical Time Series Analysis II. Statistical Aspects of Spectral Analysis of Unevenly Sampled Data, Astrophysical Journal, 263, pp. 835-853

Schanz, A., Hocke, K., and Kämpfer, 2014. N.: Daily ozone cycle in the stratosphere: global, regional and seasonal behaviour modelled with the Whole Atmosphere Community Climate Model, Atmos. Chem. Phys. Discuss., 14, 5561-5609, doi:10.5194/acpd- 14-5561-2014.

Shapiro, A. V.; Rozanov, E.; Egorova, T.; Shapiro, A. I.; Peter, Th.; Schmutz, W., 2011. Sensitivity of the Earth's middle atmosphere to short-term solar variability and its dependence on the choice of solar irradiance data set, JASTP, 73, 348S.

Snow, M., McClintock, W. E., Rottman, G., Woods, T. N., 2005. Solar Stellar Irradiance Comparison Experiment II (Solstice II): Examination of the Solar Stellar Comparison Technique, Solar Phys., 230, 295-324, doi: 10.1007/s11207-005-8763-3.

Solomon, S. C., Woods, T. N., Didkovsky, L. V., Emmert, J. T., Qian, L., 2010. Anomalously low solar extreme ultraviolet irradiance and thermospheric density during solar minimum, Geophys. Res. Lett., 37, L16103, doi:10.1029/2010GL044468.

Soukharev, B. E., L. L. Hood, 2006. Solar cycle variation of stratospheric ozone: Multiple regression analysis of long-term satellite data sets and comparisons with models, J. Geophys. Res., 111, D20314, doi:10.1029/2006JD007107.

Steinhilber, F., Beer, J., Fröhlich, C., 2009. Total solar irradiance during the Holocene, Geophys. Res. Lett., 36, L19704, doi:10.1029/2009GL040142. 


\section{ACCEPTED MANUSCRIPT}

Thuillier G., Deland M., Shapiro A., Schmutz W., Bolsée D., Melo S.M.L., 2012. The solar spectral irradiance as a function of the $\mathrm{Mg}$ ii index for atmosphere and climate modelling, Solar Physics 277, 2, 245-266.

Torrence, C., Compo, G.P., 1998. A Practical Guide to Wavelet Analysis. Bull. Amer. Meteor. Soc., 79, 61-78.

Toumi R, J. Syroka J, C. Barnes C, Lewis, P., 2001. Robust non-Gaussian statistics and longrange correlation of total ozone, Atm. Sci. Lett., Vol: 2, Pages: 94-103.

Waters, J. W., 1989. Microwave limb-sounding of Earth's upper atmosphere. Atmos. Res., 23, 391-410.

Waters, J. W., 1993. Microwave limb-sounding, Atmospheric Remote Sensing by Microwave Radiometry, M. A. Janssen, Ed., John Wiley, 383-496.

Waters, J. W. et al., 2006. The Earth Observing System Microwave Limb Sounder (EOS MLS) on the Aura satellite. Geoscience and Remote Sensing, 44(5), pp. 1075-1093.

Williams,V., Austin, J., Haigh, J. D., 2001. Model simulations of the impact of the 27-day solar rotation period on stratospheric ozone and temperature, Adv. Space Res., 27, 1933-1942, doi:10.1016/S0273-1177(01)00263-0.

Zhang, L. Y., Cui, Y. M., He, Y. L., He, H., Du, Z. L., Li, R., Wang, H. N., 2007. Longitudinal distribution of major solar flares during 1975-2005, Adv. Space Res., 40, 970975, doi:10.1016/j.asr.2006.12.052.

Zhou, S., Rottman, G. J., Miller, A. J., 1997. Stratospheric ozone response to short- and intermediate-term variations of solar UV flux, J. Geophys. Res., 102, 9003-9011, doi:10.1029/96JD03383.

Zhou, S., Miller, A. J., Hood, L. L., 2000. A partial correlation analysis of the stratospheric ozone response to 27-day solar UV variations with temperature effect removed, J. Geophys. Res., 105, 4491 - 4500, doi:10.1029/1999JD901082. 
Figures:

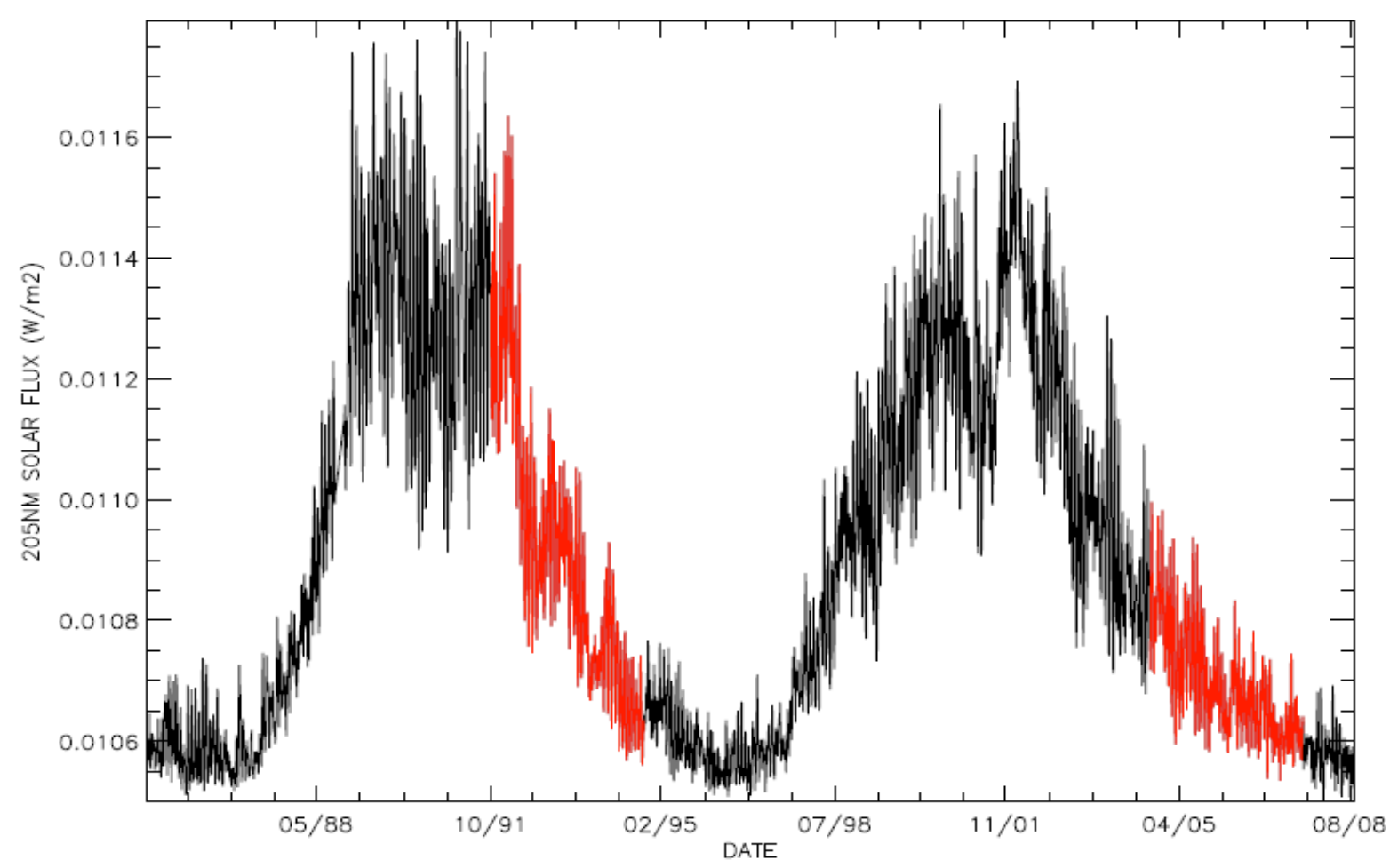

Figure 1: Temporal evolution of daily $205 \mathrm{~nm}$ solar flux from NRLSSI model over solar cycles 22 (1985-1996) and 23 (1996-2008). The two 3-year periods considered here (10/199109/1994 and 09/2004-08/2007) are highlighted in red. 

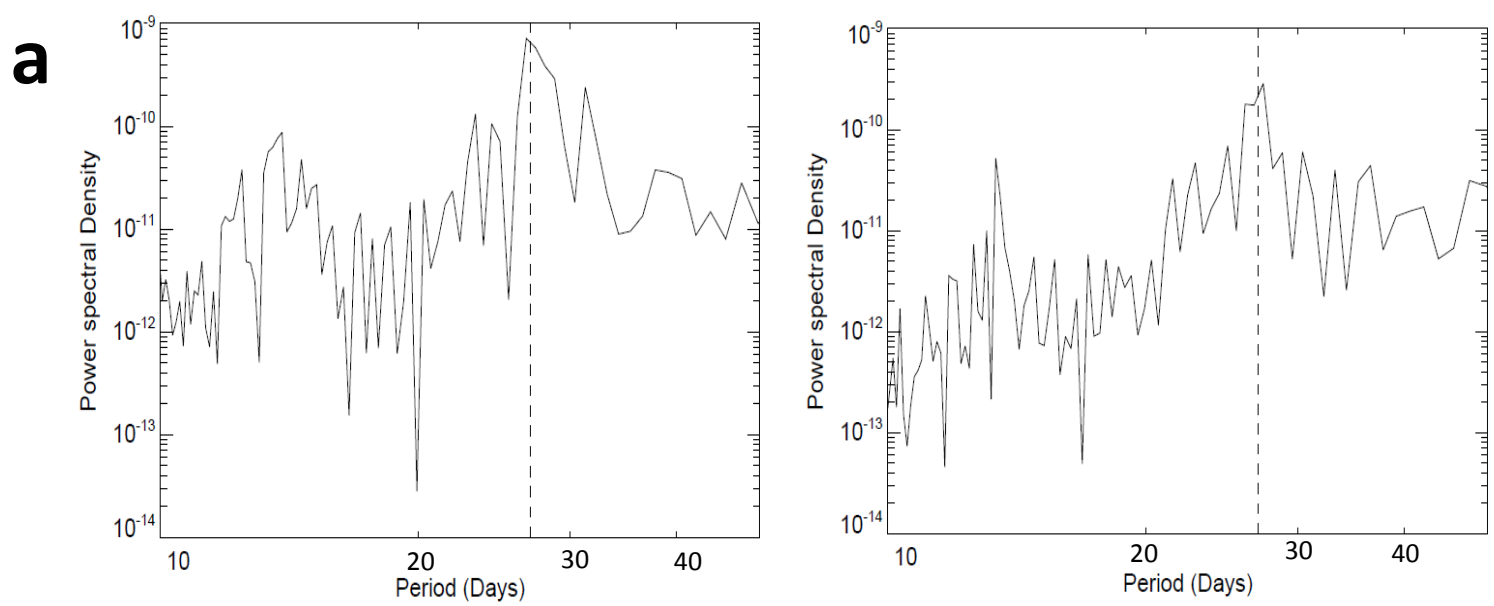

b
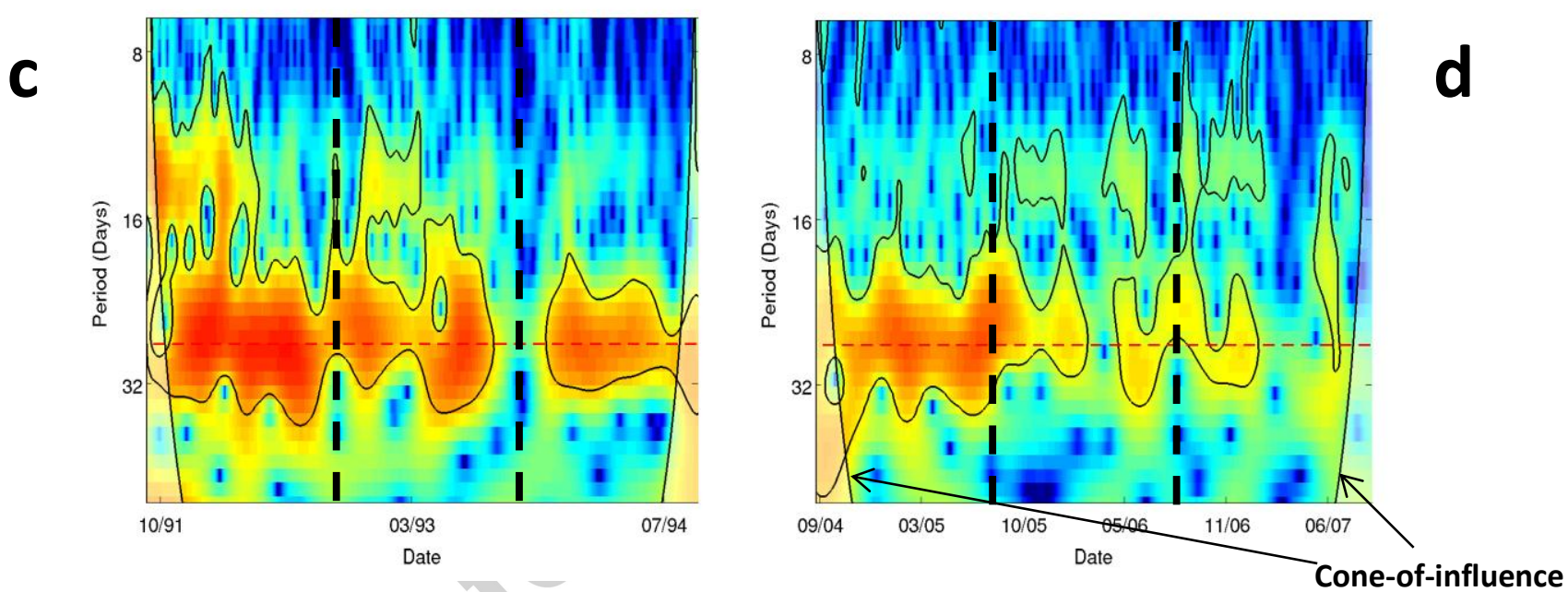

Figure 2: (Top) $205 \mathrm{~nm}$ flux FFT power spectra (from NRLSSI model) for the (a) 1991-1994 period [10/1991-09/1994] and (b) 2004-2007 period [09/2004-08/2007]. (Bottom) Timeresolved power spectra densities (or scalogram) estimated from continuous wavelet transform (CWT) for (c) the 1991-1994 period and (d) 2004-2007 period. The vertical dotted line on (a) and (b) represents the 27-day period. The thin red horizontal dashed line on (c) and (d) indicate the 27-day period; the solid contour lines represent the 95\% confidence level. The cone-of-influence on (c) and (d) is represented also by solid line on edges of scalograms and it 


\section{ACCEPTED MANUSCRIPT}

is indicated by arrows on (d) (same on (c)). The black vertical dotted lines distinguish the three 1-year intervals that are studied in section 3.3 (relative to the inter-annual analysis).
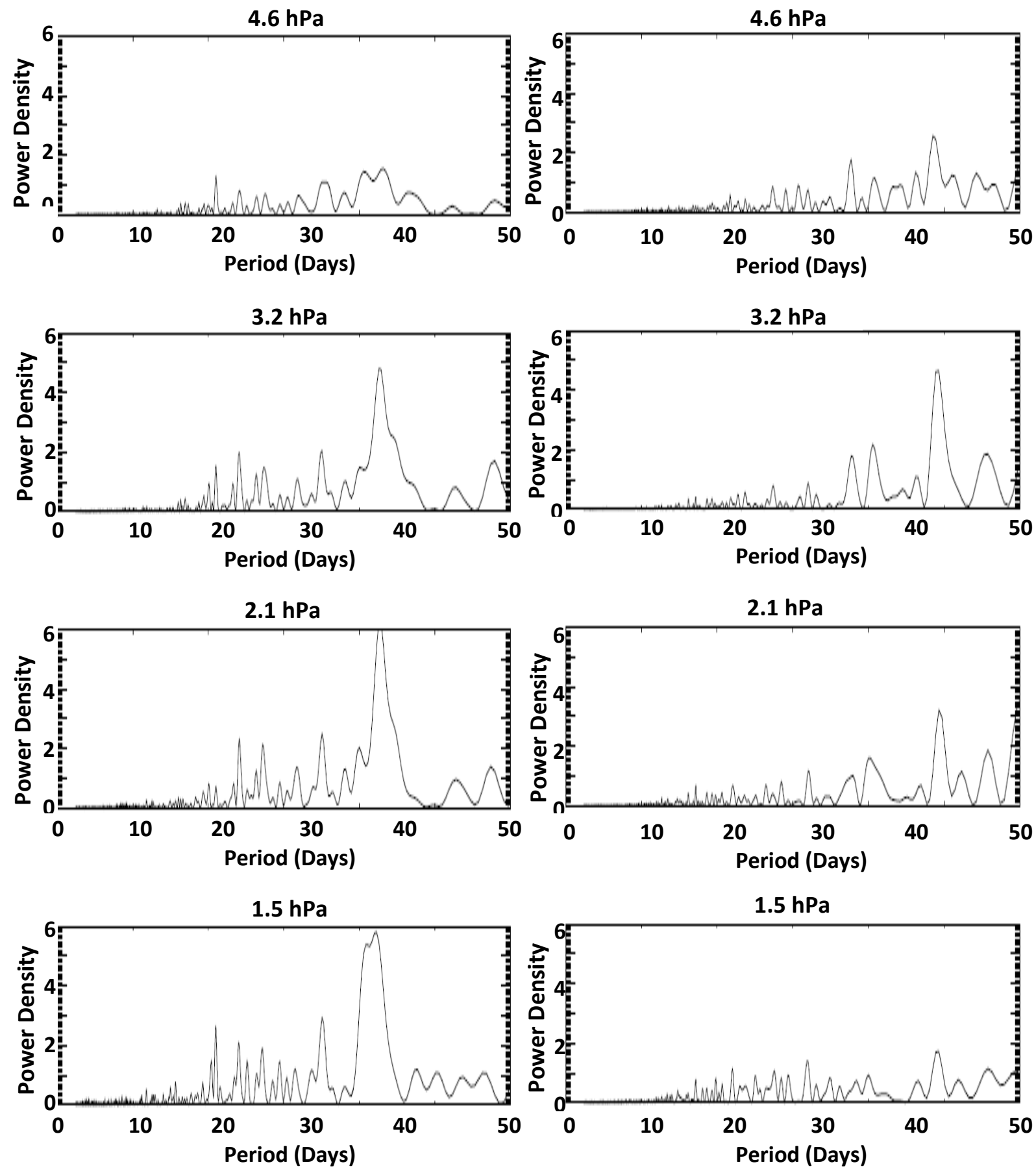


\section{ACCEPTED MANUSCRIPT}

Figure 3: Ozone Lomb-Scargle periodograms for the (left) 1991-1994 period and for the

(right) 2004-2007 period at four different pressure levels in the stratosphere (top to bottom:

4.6 hPa, 3.2 hPa, 2.1 hPa and $1.5 \mathrm{hPa})$
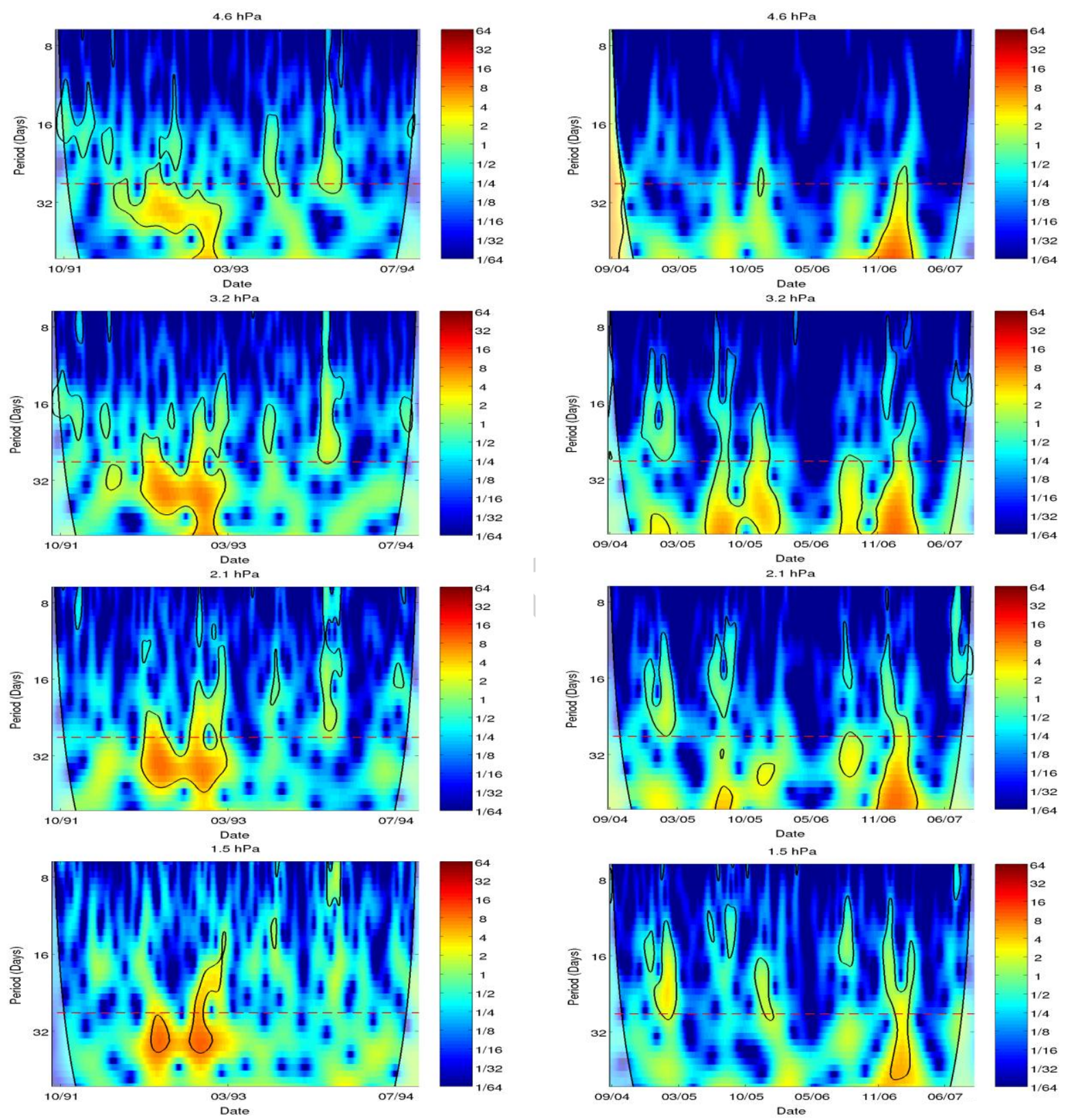

Figure 4: Time-resolved power spectra densities (or scalogram) estimated from continuous wavelet transform (CWT) of ozone for the (left) 1991-1994 period and (right) 2004-2007 


\section{ACCEPTED MANUSCRIPT}

period at four different pressure levels in the stratosphere (top to bottom: $4.6 \mathrm{hPa}, 3.2 \mathrm{hPa}$, $2.1 \mathrm{hPa}$ and $1.5 \mathrm{hPa}$ ). The red horizontal dashed line indicates the 27-day period. The solid contour lines represent the $95 \%$ confidence level.
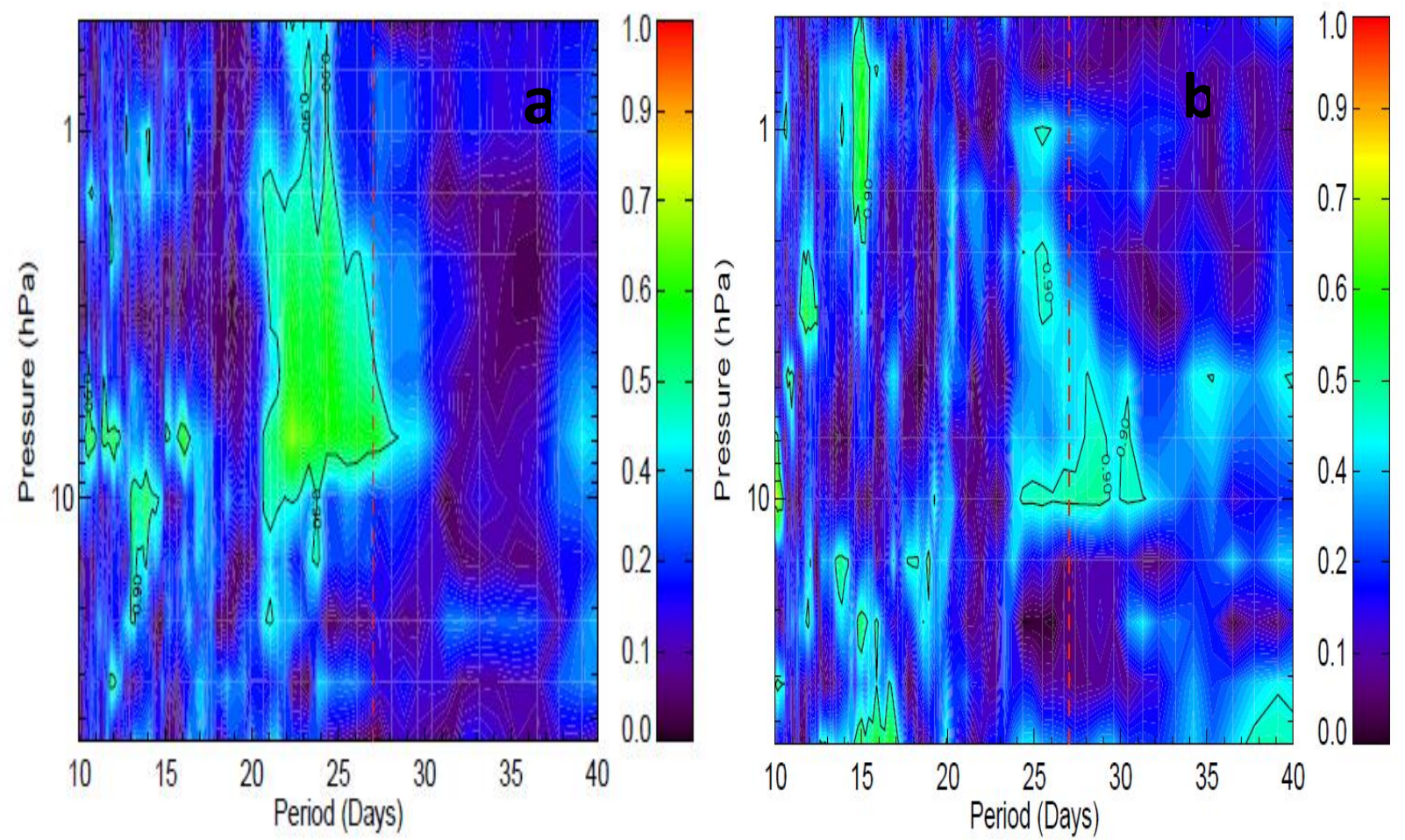

Figure 5: Mean squared coherence between ozone and $205 \mathrm{~nm}$ solar flux as a function of period and pressure for the (left) 1991-1994 period and for the (right) 2004-2007 period. Contour lines represent the $90 \%$ confidence level. The red vertical dashed line indicates the 27-day period. 
Cvcle 22 (1991-94 beriod)
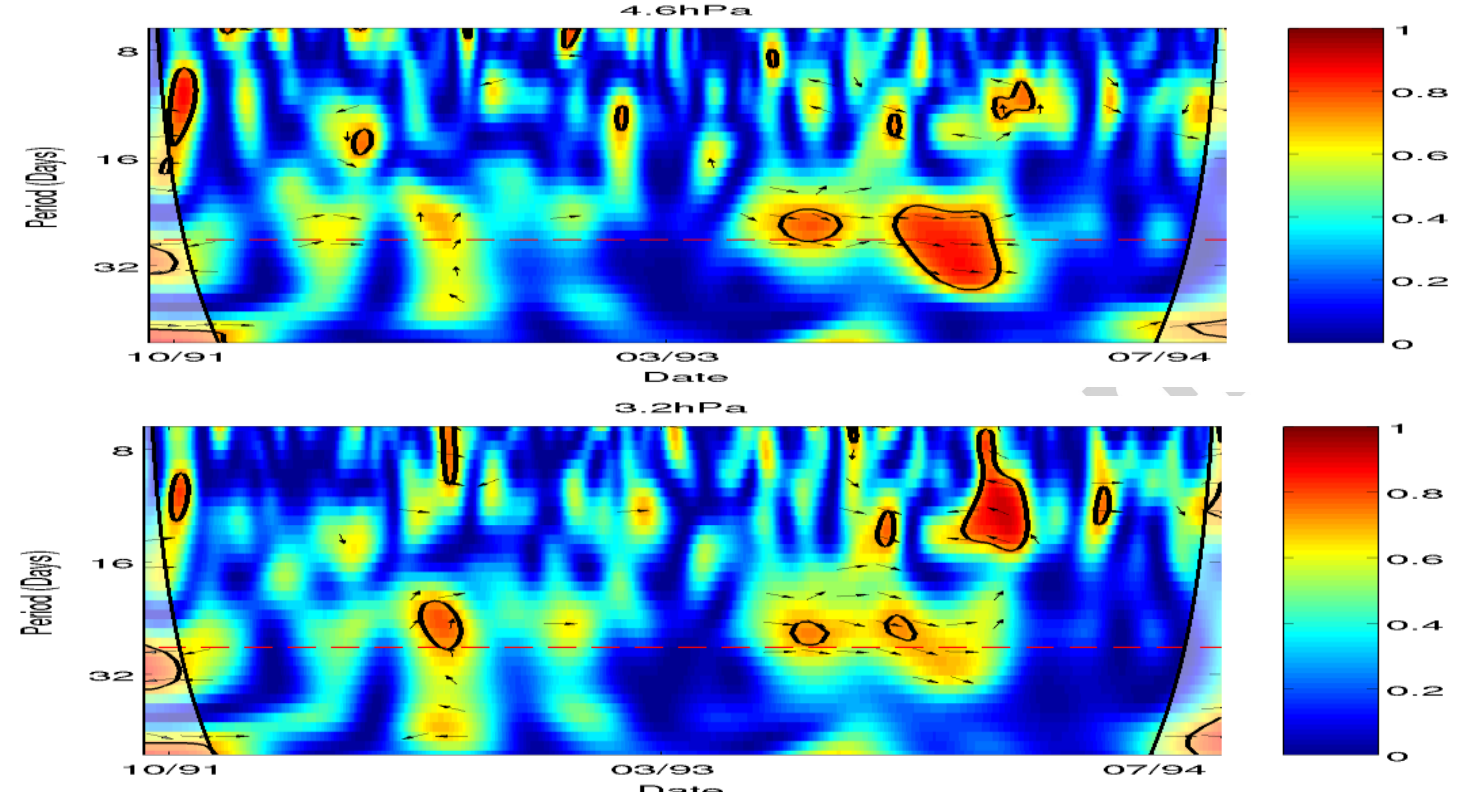

Cvcle 23 (2004-07 period)
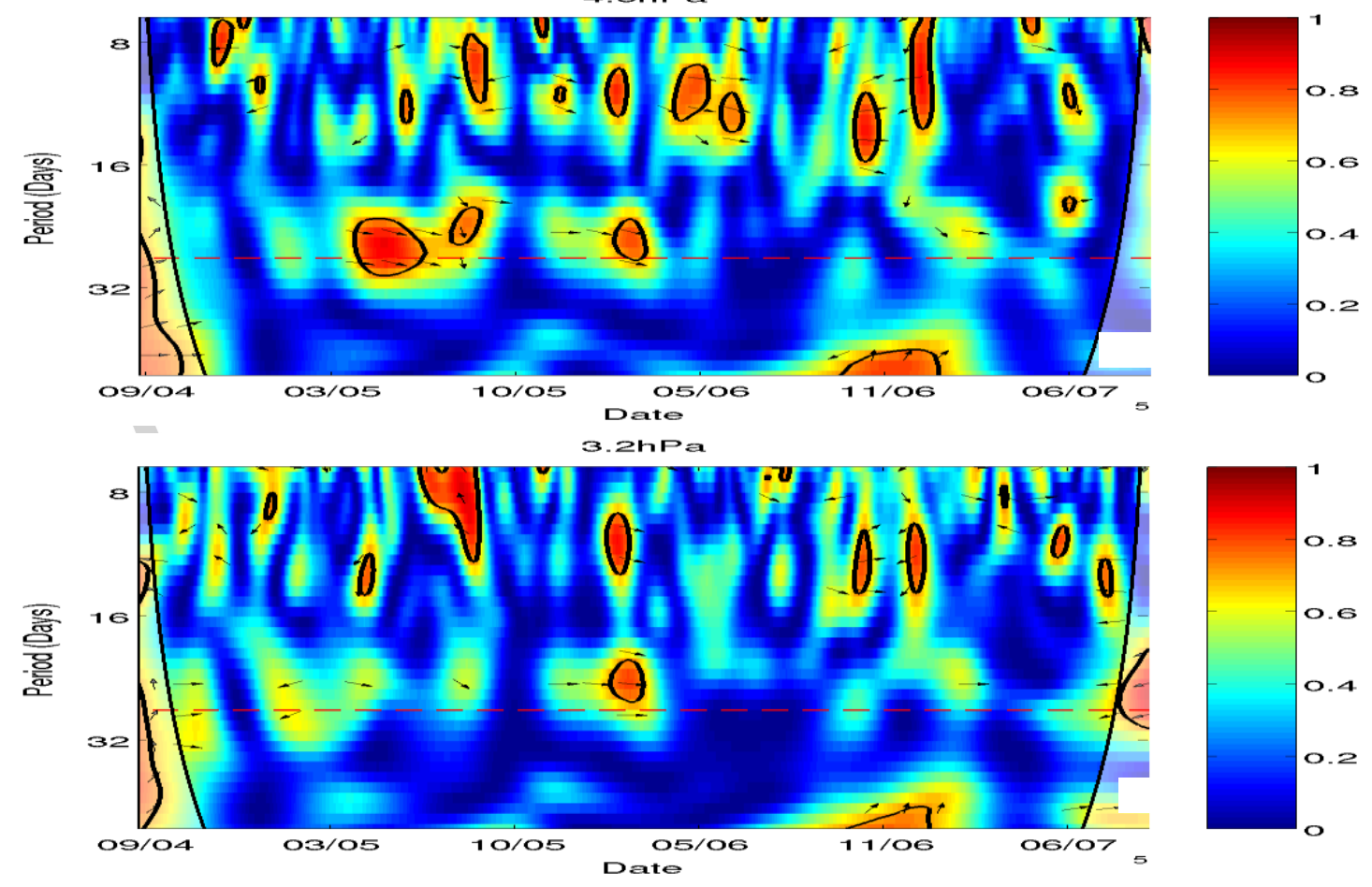
Figure 6: Wavelet Transform Coherence (WTC) between ozone and $205 \mathrm{~nm}$ flux for the (two top panels) 1991-1994 period and for (two bottom panels) 2004-2007 period at two different pressure levels in the stratosphere $(4.6 \mathrm{hPa}$ and $3.2 \mathrm{hPa})$. The red horizontal dashed line indicates the 27-day period. Solid contour lines represent the $95 \%$ confidence level. Arrows represent the relative phase between solar and ozone time series (right arrow: in-phase, left arrow: out-of-phase, down arrow: solar leading ozone). 


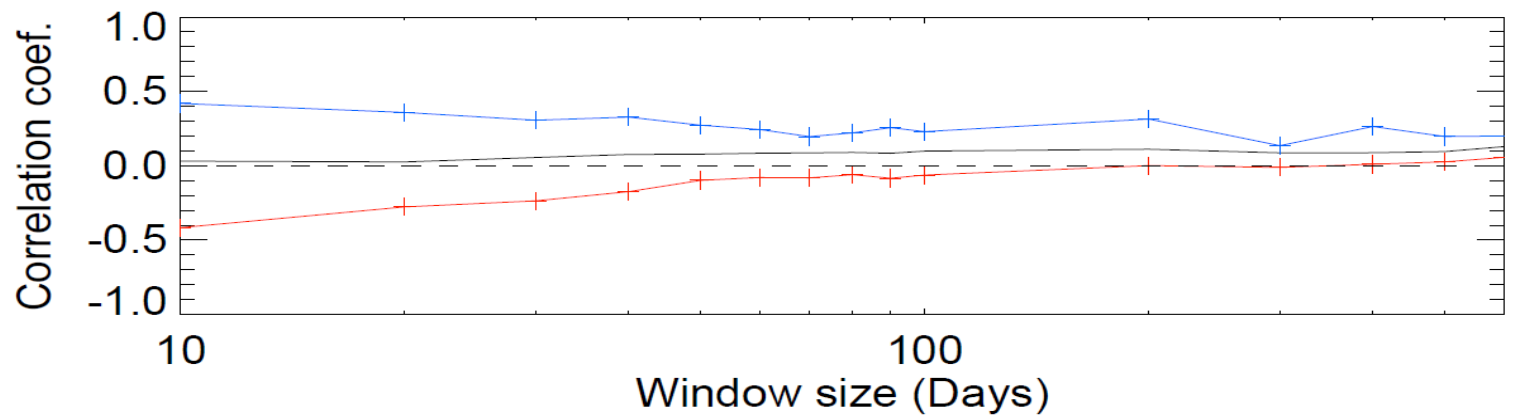

a
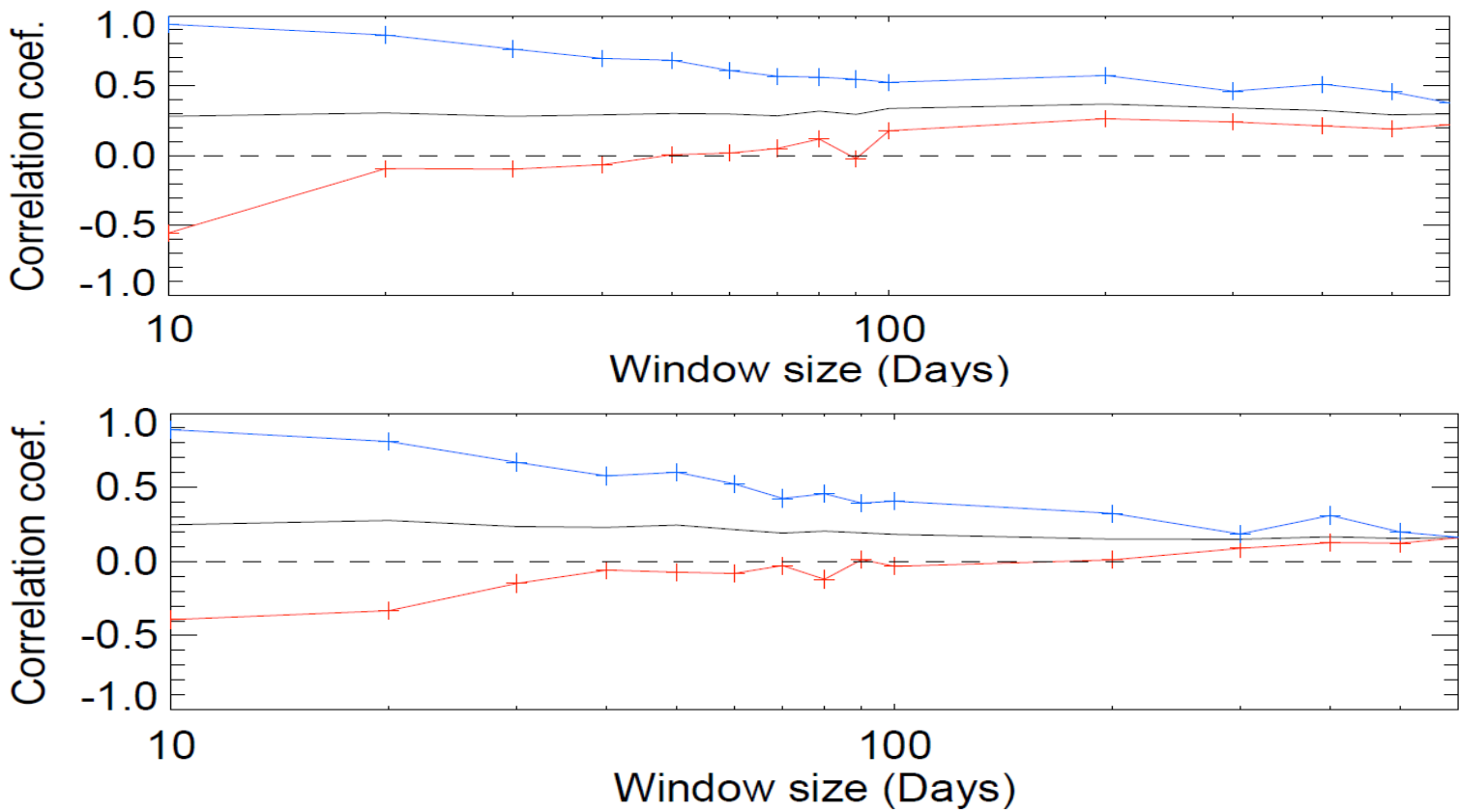

C

Figure 7: Mean linear correlation coefficient (a) between two random time series, and between the $205 \mathrm{~nm}$ flux and ozone (at $4.6 \mathrm{hPa}$ ) for the (b) 1991-1994 period and for the (c) 2004-2007 period as a function of the window size. The black solid lines represent the mean correlation, the colored solid lines represent the 0.75 (blue) and 0.25 (red) quantiles and the dashed line represents the zero correlation. The total sample size is 1095 days and each window is shifted by half of the window size. Therefore the first window size value on the 


\section{ACCEPTED MANUSCRIPT}

abscissa (i.e. 10 days) correspond to about 219 windows and the last window size value (600 days) on the abscissa corresponds to 2 windows. For a given window size, correlations are calculated over all the windows and then mean and quantiles are calculated from the correlation distribution. The ozone and $205 \mathrm{~nm}$ flux time series had been digitally filtered (see section 3).
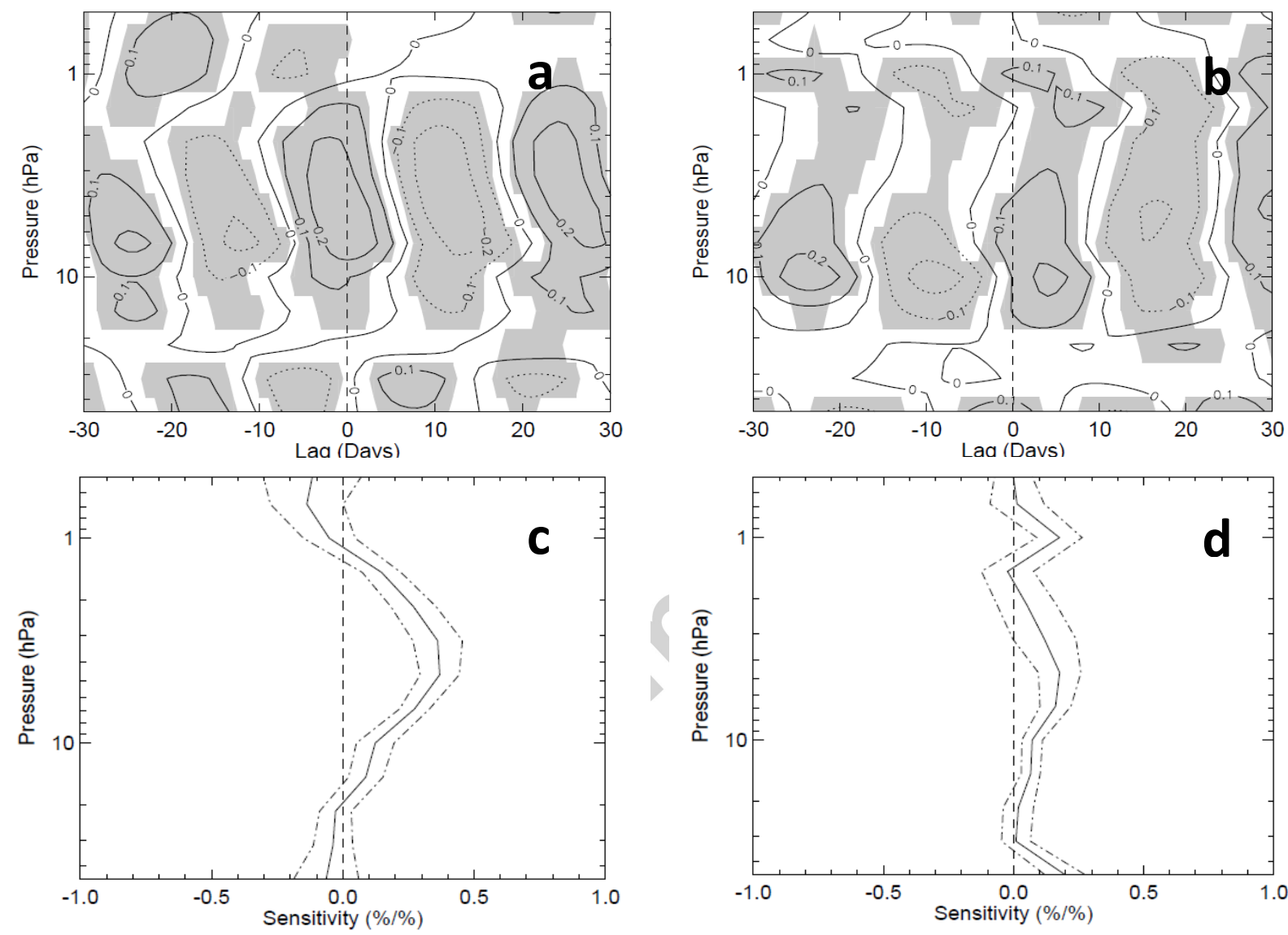

Figure 8: (Top) Cross-correlation between ozone and $205 \mathrm{~nm}$ solar flux as a function of time lag (days) and pressure (hPa) for the (a) 1991-1994 period and for (b) 2004-2007 period. (Bottom) Ozone sensitivity to $205 \mathrm{~nm}$ flux (\% change in ozone for 1\% change in $205 \mathrm{~nm}$ flux) as a function of pressure for (c) cycle 22 and for (d) cycle 23. The shaded areas in (a) and (b) represent areas with a 95\% significant level. The dash-dotted lines in (c) and (d) represent the 2- $\sigma$ error. The ozone and $205 \mathrm{~nm}$ flux time series had been digitally filtered (see section 3). 


\section{ACCEPTED MANUSCRIPT}
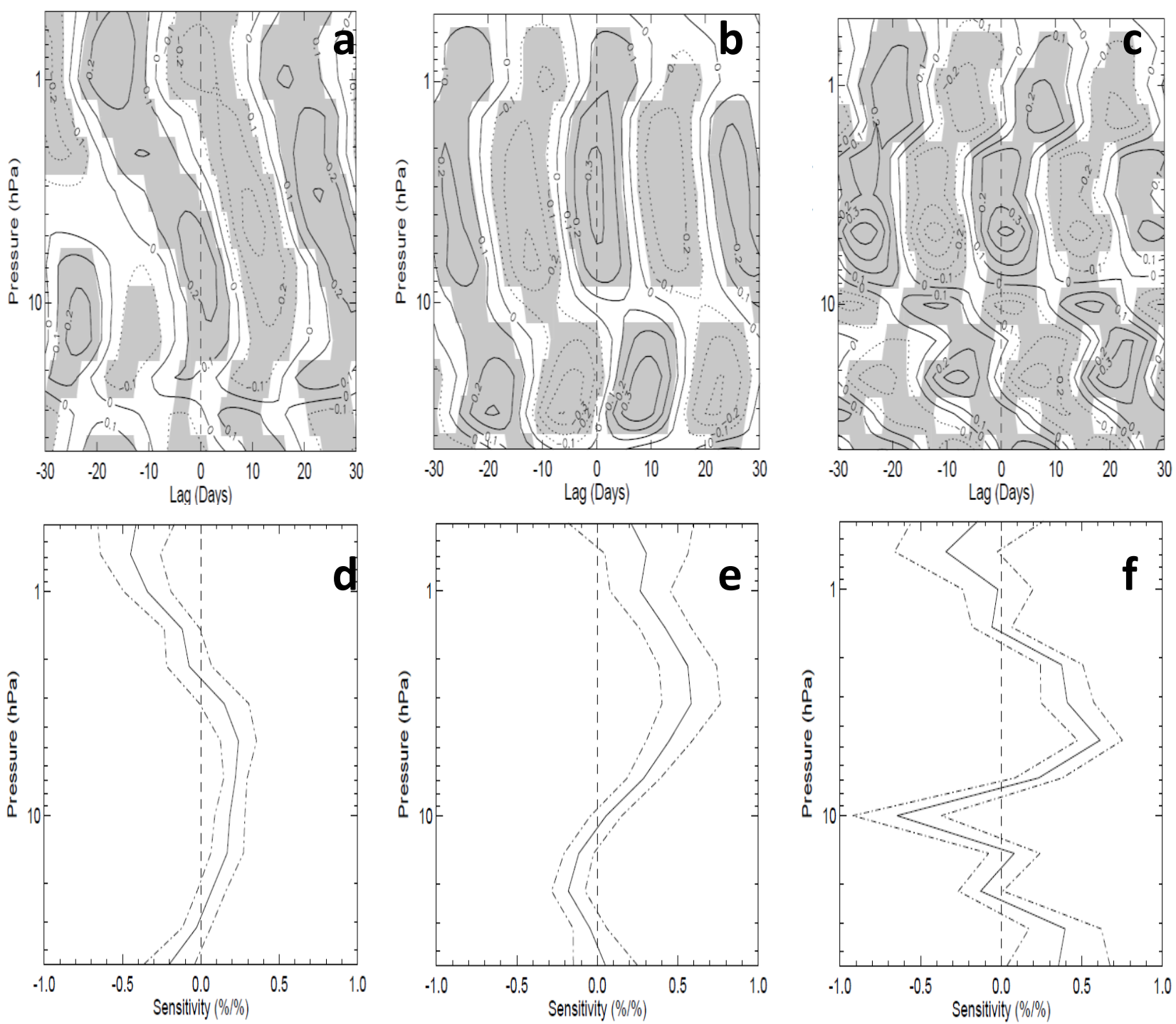

Figure 9: Same as Figure 8 but for (left) the first year (10/1991-09/1992), (middle) second year (10/1992-09/1993), and (right) third year (10/1993-09/1994) of the 1991-1994 period. The shaded areas in (a), (b) and (c) represent areas with a 95\% confidence level. The dash- 


\section{ACCEPTED MANUSCRIPT}

dotted lines in (d), (e) and (f) represent the 2- $\sigma$ error. The ozone and $205 \mathrm{~nm}$ flux time series had been digitally filtered.
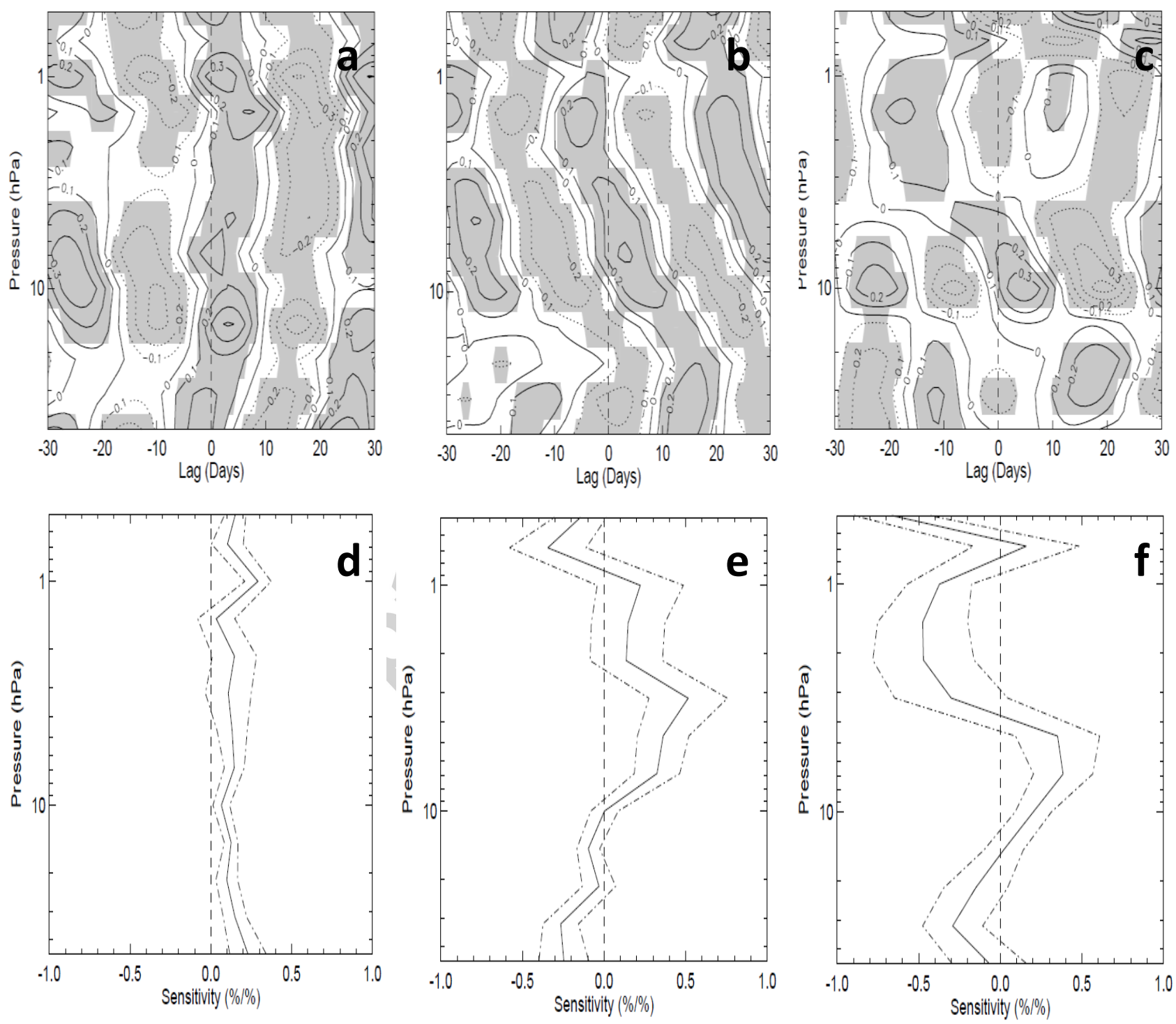

Figure 10: Same as Figure 9 but for (left) the first year (09/2004-08/2005), (middle) second year (09/2005-08/2006), and (right) third year (09/2006-08/2007) of the 2004-2007 period. The shaded areas in (a), (b) and (c) represent areas with a 95\% confidence level. The dash- 


\section{ACCEPTED MANUSCRIPT}

dotted lines in (d), (e) and (f) represent the 2- $\sigma$ error. The ozone and $205 \mathrm{~nm}$ flux time series had been digitally filtered.
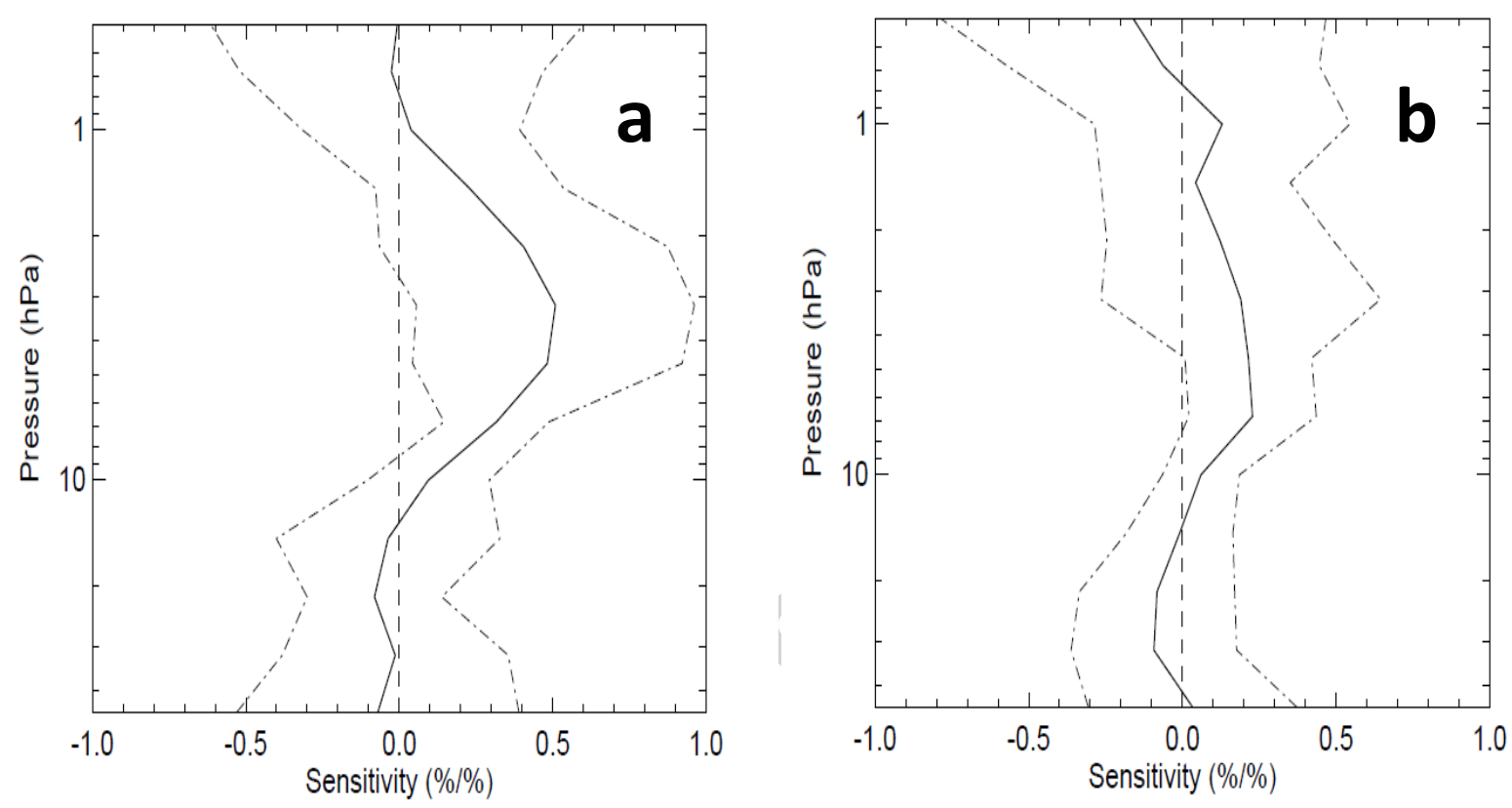

Figure 11: Mean ozone sensitivity to $205 \mathrm{~nm}$ flux (\% change in ozone for $1 \%$ change in 205 nm flux) as a function of pressure for the (left) 1991-1994 period and for (d) 2004-2007 period. The mean sensitivity profile is calculated by averaging 24 sensitivity profiles (calculated over 24 1-year intervals obtained by shifting a 1-year sliding window by a month over the 3-year periods). The dash-dotted lines indicate the $2-\sigma$ deviations. 
Tables:

\begin{tabular}{|c|c|c|c|c|}
\hline $\begin{array}{c}\text { Pressure levels } \\
\text { (hPa) }\end{array}$ & 10/1991 - 09/1994 & 10/1991 - 09/1992 & $10 / 1992-09 / 1993$ & $10 / 1993-09 / 1994$ \\
\hline 10 & $0.10 \pm 0.06$ & $0.20 \pm 0.10$ & $0.06 \pm 0.10$ & $-0.24 \pm 0.10$ \\
\hline 6.8 & $0.28 \pm 0.06$ & $0.30 \pm 0.10$ & $0.28 \pm 0.10$ & $0.16 \pm 0.10$ \\
\hline 4.6 & $0.29 \pm 0.06$ & $0.21 \pm 0.10$ & $0.31 \pm 0.10$ & $0.42 \pm 0.10$ \\
\hline 3.2 & $0.23 \pm 0.06$ & $0.10 \pm 0.10$ & $0.32 \pm 0.10$ & $0.25 \pm 0.10$ \\
\hline 2.1 & $0.19 \pm 0.06$ & $-0.05 \pm 0.10$ & $0.31 \pm 0.10$ & $0.29 \pm 0.10$ \\
\hline 1.5 & $0.12 \pm 0.06$ & $-0.11 \pm 0.10$ & $0.26 \pm 0.10$ & $0.05 \pm 0.10$ \\
\hline
\end{tabular}

Table 1: Correlation coefficients and associated $2-\sigma$ errors between ozone (at six different pression levels) and $205 \mathrm{~nm}$ flux for cycle 22. The second column refers to the whole 3-year period, the third column to the first year of the period, the forth to the second year and the fifth to the third year. The ozone and $205 \mathrm{~nm}$ flux time series had been digitally filtered (see section 3). 
ACCEPTED MANUSCRIPT

\begin{tabular}{|c|c|c|c|c|}
\hline $\begin{array}{c}\text { Pressure levels } \\
\text { (hPa) }\end{array}$ & $09 / 2004-08 / 2007$ & $09 / 2004-08 / 2005$ & $09 / 2005-08 / 2006$ & 09/2006 - 08/2007 \\
\hline 10 & $0.11 \pm 0.06$ & $0.13 \pm 0.10$ & $0.00 \pm 0.10$ & $0.19 \pm 0.10$ \\
\hline 6.8 & $0.16 \pm 0.06$ & $0.24 \pm 0.10$ & $0.24 \pm 0.10$ & $0.22 \pm 0.10$ \\
\hline 4.6 & $0.13 \pm 0.06$ & $0.15 \pm 0.10$ & $0.23 \pm 0.10$ & $0.14 \pm 0.10$ \\
\hline 3.2 & $0.06 \pm 0.06$ & $0.08 \pm 0.10$ & $0.22 \pm 0.10$ & $-0.09 \pm 0.10$ \\
\hline 2.1 & $0.03 \pm 0.06$ & $0.11 \pm 0.10$ & $0.06 \pm 0.10$ & $-0.16 \pm 0.10$ \\
\hline 1.5 & $-0.01 \pm 0.06$ & $-0.03 \pm 0.10$ & $0.07 \pm 0.10$ & $-0.18 \pm 0.10$ \\
\hline
\end{tabular}

Table 2: Same as Table 1 but for cycle 23.

- Correlation is not found to bear any relation with solar rotational forcing

- Strong inter-annual variability in solar rotational signal contained in ozone time series

- Ozone response is stronger during the descending phase of cycle 22 than cycle 23

- Other sources of variability operate on the rotational spectral range 